\title{
Interlaboratory comparison study of calibration standards for foraminiferal $\mathrm{Mg} / \mathrm{Ca}$ thermometry
}

\section{Greaves}

Department of Earth Sciences, University of Cambridge, Downing Street, Cambridge CB2 3EQ, UK

(mg109@esc.cam.ac.uk)

N. Caillon and H. Rebaubier

LSCE/IPSL, UMR CNRS, CEA, UVSQ, Bâtiment 12, avenue de la Terrasse, F-91198 Gif sur Yvette, France

\section{G. Bartoli}

Institute für Geowissenschaften, Kiel University, Olshausenstrasse 40, D-24118 Kiel, Germany

Now at ETH Zentrum, Chemie Altbau, CAB E64, Universitätstrasse 6, CH-8092 Zurich, Switzerland

\section{S. Bohaty}

Department of Ocean Sciences, University of California, Santa Cruz, Santa Cruz, California 95060, USA

Now at School of Ocean and Earth Science, University of Southampton, National Oceanography Centre, European Way, Southampton SO14 3ZH, UK

\section{Cacho}

GRC Geociències Marines, Department of Stratigraphy, Paleontology and Marine Geosciences, University of Barcelona, C/Martí i Franquès, s/n, E-08028 Barcelona, Spain

\section{Clarke}

School of Ocean Sciences, College of Natural Sciences, Bangor University, Askew Street, Menai Bridge, Isle of Anglesey, Wales LL59 5EY, UK

\section{Cooper}

National Oceanography Centre, European Way, Southampton SO14 3ZH, UK

\section{Daunt}

Department of Earth Sciences, University of Cambridge, Downing Street, Cambridge CB2 3EQ, UK

\section{Delaney}

Department of Ocean Sciences, University of California, Santa Cruz, Santa Cruz, California 95060, USA

\section{P. deMenocal}

Lamont-Doherty Earth Observatory, Columbia University, Geoscience 211, Route 9W, Palisades, New York 10964, USA

\section{A. Dutton and S. Eggins}

Research School of Earth Sciences, Australian National University, 1 Mills Road, Canberra, ACT 0200, Australia 


\section{H. Elderfield}

Department of Earth Sciences, University of Cambridge, Downing Street, Cambridge CB2 3EQ, UK

\section{Garbe-Schoenberg}

Institute für Geowissenschaften, Kiel University, Olshausenstrasse 40, D-24118 Kiel, Germany

\section{E. Goddard}

College of Marine Science, University of South Florida, St. Petersburg, Florida 33701, USA

\section{Green}

National Oceanography Centre, European Way, Southampton SO14 3ZH, UK

\section{J. Groeneveld}

IFM-GEOMAR, Wischhofstrasse 1-3, D-24148 Kiel, Germany

Now at Research Center Ocean Margins, University of Bremen, D-28359 Bremen, Germany

\section{Hastings}

Collegium of Natural Sciences, Eckerd College, 4200 54th Avenue South, St. Petersburg, Florida 33713, USA

\section{E. Hathorne}

Department of Earth Sciences, Open University, Milton Keynes, UK

Now at Research Center Ocean Margins, University of Bremen, D-28359 Bremen, Germany

\section{K. Kimoto}

Institute of Observational Research for Global Change, JAMSTEC, 2-15, Natsushima-cho, Yokosuka, 247-0061 Japan

\section{G. Klinkhammer}

College of Oceanography, Oregon State University, Oceanography Administration Building 104, Corvallis, Oregon 97331, USA

\section{Labeyrie}

LSCE/IPSL, UMR CNRS, CEA, UVSQ, Bâtiment 12, avenue de la Terrasse, F-91198 Gif sur Yvette, France

\section{W. Lea}

Department of Geological Sciences, University of California, Santa Barbara, Mail Stop 9630, Santa Barbara, California 93106, USA

\section{T. Marchitto}

INSTAAR, University of Colorado, Campus Box 450, Boulder, Colorado 80309, USA

\section{A. Martínez-Botí and P. G. Mortyn}

ICTA, Universitat Autònoma de Barcelona, Edifici Cn-Campus UAB, E-08193 Bellaterra, Spain

\section{Y. Ni}

Department of Earth Sciences, University of Bristol, Bristol, UK

Now at Research Institute of Petroleum Exploration and Development, PetroChina, 20 Xueyuan Road, Haidian District, Beijing, China, 100083

\section{Nuernberg}

IFM-GEOMAR, Wischhofstrasse 1-3, D-24148 Kiel, Germany

\section{G. Paradis}

Department of Geological Sciences, University of California, Santa Barbara, Mail Stop 9630, Santa Barbara, California 93106, USA 


\section{Pena}

GRC Geociències Marines, Department of Stratigraphy, Paleontology and Marine Geosciences, University of Barcelona, C/Martí i Franquès, s/n, E-08028 Barcelona, Spain

\section{T. Quinn}

College of Marine Science, University of South Florida, St. Petersburg, Florida 33701, USA

\section{Y. Rosenthal}

Institute of Marine and Coastal Sciences, Department of Geology, Rutgers, State University of Nerw Jersey, 71 Dudley Road, New Brunswick, New Jersey 08901, USA

\section{A. Russell}

Department of Geology, University of California, Davis, One Shields Avenue, Davis, California 95616, USA

\section{T. Sagawa}

Center for Advanced Marine Core Research, Kochi University, B200 Monobe, Nankoku, Kochi 783-8502, Japan

\section{S. Sosdian}

Institute of Marine and Coastal Sciences, Department of Geology, Rutgers, State University of New Jersey, 71 Dudley Road, New Brunswick, New Jersey 08901, USA

\section{Stott}

Department of Earth Sciences, University of South California, Los Angeles 90089, California, USA

\section{K. Tachikawa}

CEREGE, UMR UAMIII, CNRS, CDF, IRD, Europôle Méditerranéen de l'Arbois, BP 80, F-13545 Aix-en-

Provence, France

\section{E. Tappa and R. Thunell}

Department of Geological Sciences, University of South Carolina, 701 Sumter Street, EWSC Room 617, Columbia, South Carolina 29208, USA

\section{P. A. Wilson}

National Oceanography Centre, European Way, Southampton SO14 3ZH, UK

[1] An interlaboratory study of $\mathrm{Mg} / \mathrm{Ca}$ and $\mathrm{Sr} / \mathrm{Ca}$ ratios in three commercially available carbonate reference materials (BAM RS3, CMSI 1767, and ECRM 752-1) was performed with the participation of 25 laboratories that determine foraminiferal $\mathrm{Mg} / \mathrm{Ca}$ ratios worldwide. These reference materials containing $\mathrm{Mg} / \mathrm{Ca}$ in the range of foraminiferal calcite $(0.8 \mathrm{mmol} / \mathrm{mol}$ to $6 \mathrm{mmol} / \mathrm{mol})$ were circulated with a dissolution protocol for analysis. Participants were asked to make replicate dissolutions of the powdered samples and to analyze them using the instruments and calibration standards routinely used in their laboratories. Statistical analysis was performed in accordance with the International Standardization Organization standard 5725, which is based on the analysis of variance (ANOVA) technique. Repeatability $\left(\mathrm{RSD}_{\mathrm{r}} \%\right.$ ), an indicator of intralaboratory precision, for $\mathrm{Mg} / \mathrm{Ca}$ determinations in solutions after centrifuging increased with decreasing $\mathrm{Mg} / \mathrm{Ca}$, ranging from $0.78 \%$ at $\mathrm{Mg} / \mathrm{Ca}=5.56 \mathrm{mmol} / \mathrm{mol}$ to $1.15 \%$ at $\mathrm{Mg} / \mathrm{Ca}=0.79 \mathrm{mmol} / \mathrm{mol}$. Reproducibility $\left(\mathrm{RSD}_{\mathrm{R}} \%\right)$, an indicator of the interlaboratory method precision, for $\mathrm{Mg} / \mathrm{Ca}$ determinations in centrifuged solutions was noticeably worse than repeatability, ranging from $4.5 \%$ at $\mathrm{Mg} / \mathrm{Ca}=5.56 \mathrm{mmol} / \mathrm{mol}$ to $8.7 \%$ at $\mathrm{Mg} / \mathrm{Ca}=0.79 \mathrm{mmol} / \mathrm{mol}$. Results of this study show that interlaboratory variability is dominated by inconsistencies among instrument calibrations and highlight the need to improve interlaboratory compatibility. Additionally, the study confirmed the suitability of these solid standards as reference materials for foraminiferal $\mathrm{Mg} / \mathrm{Ca}$ (and $\mathrm{Sr} / \mathrm{Ca}$ ) determinations, provided that appropriate procedures are adopted to minimize and to monitor possible contamination from silicate mineral phases. 
Components: 11,680 words, 9 figures, 7 tables.

Keywords: $\mathrm{Mg} / \mathrm{Ca}$ thermometry; intercalibration; reference materials; paleoceanography; carbonates.

Index Terms: 4825 Oceanography: Biological and Chemical: Geochemistry; 4875 Oceanography: Biological and Chemical: Trace elements (0489); 4924 Paleoceanography: Geochemical tracers.

Received 12 February 2008; Revised 8 May 2008; Accepted 6 June 2008; Published 19 August 2008.

Greaves, M., et al. (2008), Interlaboratory comparison study of calibration standards for foraminiferal $\mathrm{Mg} / \mathrm{Ca}$ thermometry, Geochem. Geophys. Geosyst., 9, Q08010, doi:10.1029/2008GC001974.

\section{Introduction}

[2] Reconstruction of past ocean temperatures from magnesium/calcium ratios in foraminiferal calcite has become an established technique during recent years [e.g., Nurnberg et al., 1996; Hastings et al., 1998; Lea et al., 1999; Mashiotta et al., 1999; Elderfield and Ganssen, 2000; Rosenthal et al., 2000; Dekens et al., 2002; Anand et al., 2003]. $\mathrm{Mg} / \mathrm{Ca}$ ratios in foraminiferal calcite are now measured routinely by different laboratories and comparability of results is an important issue.

[3] A consequence of the exponential relationship between $\mathrm{Mg} / \mathrm{Ca}$ and temperature in foraminiferal calcite is that in order to ensure the accuracy of calculated temperatures, the relative measurement precision, expressed as a percentage of the measured ratio, must be maintained across the range of $\mathrm{Mg} / \mathrm{Ca}$ ratios from low to high values. This is contrary to the usual situation in analytical methods [Horwitz, 1982], where relative measurement precision becomes worse with decreasing values. Increasing interest in temperatures calculated from the low $\mathrm{Mg} / \mathrm{Ca}$ ratios found in benthic [Billups and Schrag, 2002, 2003; Martin et al., 2002; Marchitto and deMenocal, 2003; Lear et al., 2004; Elderfield et al., 2006] and cold water planktonic foraminifera [Pak et al., 2004; von Langen et al., 2005; Meland et al., 2006; Nyland et al., 2006] further emphasizes the need for compatibility of $\mathrm{Mg} / \mathrm{Ca}$ measurements between different laboratories.

[4] An interlaboratory comparison study conducted by Rosenthal et al. [2004] examined the reproducibility of $\mathrm{Mg} / \mathrm{Ca}$ measurements within and between laboratories in foraminiferal calcite and in synthetic standard solutions. The study additionally included $\mathrm{Sr} / \mathrm{Ca}$ because of the interest in studying secular variations in seawater $\mathrm{Sr} / \mathrm{Ca}$ [Martin et al., 1999; Stoll et al., 1999; Elderfield et al., 2000; Shen et al., 2001] and growing potential for fora- miniferal $\mathrm{Sr} / \mathrm{Ca}$ thermometry in select genera [Mortyn et al., 2005]. Results showed that for the analyses of standard solutions, within laboratory instrumental precisions were usually better than $0.5 \%$ for measurements of both $\mathrm{Mg} / \mathrm{Ca}$ and $\mathrm{Sr} /$ $\mathrm{Ca}$, but interlaboratory precisions were significantly worse with relative standard deviations obtained of up to $3.4 \%$ for $\mathrm{Mg} / \mathrm{Ca}$ and $1.8 \%$ for $\mathrm{Sr} / \mathrm{Ca}$. Among the conclusions of that interlaboratory study were the need for standards calibration among laboratories and the desirability of developing an agreed solid standard which could be used by laboratories in a manner analogous to the way reference standards are used in isotope analyses.

[5] The accuracy of standard solutions for element ratio determinations and the potential of commercially available carbonate reference materials for application to foraminiferal $\mathrm{Mg} / \mathrm{Ca}$ (and $\mathrm{Sr} / \mathrm{Ca}$ ) determinations were investigated by Greaves et al. [2005]. These authors demonstrated that the errors involved in the preparation of instrument calibration standards for $\mathrm{Mg} / \mathrm{Ca}$ and $\mathrm{Sr} / \mathrm{Ca}$ determinations contribute significantly to interlaboratory analytical precision and proposed a limestone certified reference material (ECRM 752-1), containing $\mathrm{Mg} / \mathrm{Ca}$ within the range of foraminiferal calcite $(\mathrm{Mg} / \mathrm{Ca}=3.75 \mathrm{mmol} / \mathrm{mol})$, as a consistency standard which could be used within and between laboratories.

[6] Here we present the results of an interlaboratory study where three solid materials containing $\mathrm{Mg} / \mathrm{Ca}$ in the range of foraminiferal calcite $(0.8 \mathrm{mmol} / \mathrm{mol}$ to $6 \mathrm{mmol} / \mathrm{mol})$ were analyzed by 25 participating laboratories. The advantage of circulating solid standards for intercalibration, rather than standard solutions, is that solid standards overcome the risk inherent in circulating small volumes of liquids that may not retain their initial compositions by the time they are analyzed. This must be balanced against stringent homogeneity and purity requirements for solid standards 
Table 1. Certified Reference Materials

\begin{tabular}{|c|c|c|c|c|c|c|c|c|c|}
\hline \multirow[b]{2}{*}{ CRM } & \multirow[b]{2}{*}{ Certified by ${ }^{\mathrm{a}}$} & \multicolumn{8}{|c|}{ Quoted Element Concentrations (wt \%) } \\
\hline & & $\mathrm{Ca}$ & $\mathrm{Mg}$ & $\mathrm{Sr}$ & $\mathrm{Al}$ & $\mathrm{Fe}$ & $\mathrm{Mn}$ & $\mathrm{Si}$ & $\mathrm{Ti}$ \\
\hline CM 1767 & CMSI & 39.4 & 0.14 & - & 0.03 & 0.06 & - & 0.21 & - \\
\hline ECRM 752-1 & BAS & 39.6 & 0.093 & 0.016 & 0.033 & 0.016 & 0.01 & 0.33 & 0.005 \\
\hline \multirow[t]{3}{*}{ BAM RS3 } & BAM & 40.0 & 0.018 & 0.017 & $<0.001$ & $<0.001$ & - & - & - \\
\hline & & & \multicolumn{7}{|c|}{ Calculated Ratios $(\mathrm{mmol} / \mathrm{mol})$} \\
\hline & Material & & $\mathrm{Mg} / \mathrm{Ca}$ & $\mathrm{Sr} / \mathrm{Ca}$ & $\mathrm{Al} / \mathrm{Ca}$ & $\mathrm{Fe} / \mathrm{Ca}$ & $\mathrm{Mn} / \mathrm{Ca}$ & $\mathrm{Si} / \mathrm{Ca}$ & $\mathrm{Ti} / \mathrm{Ca}$ \\
\hline CM 1767 & limestone & & 6.1 & - & 1.0 & 1.0 & - & 7.6 & - \\
\hline ECRM 752-1 & limestone & & 3.9 & 0.19 & 1.2 & 0.3 & 0.15 & 11.9 & 0.12 \\
\hline BAM RS3 & calcite & & 0.8 & 0.20 & $<0.02$ & $<0.01$ & - & - & - \\
\hline
\end{tabular}

${ }^{\mathrm{a}}$ BAM, Bundesanstalt für Materialforschung und -prufung, Germany; BAS, Bureau of Analysed Samples Ltd, Newnham Hall, Newby, Middlesborough, UK; CMSI, China Metallurgical Standardization Research Institute, Beijing.

[Greaves et al., 2005]. Therefore, there were two objectives to the current study; first, compare instrumental standards calibrations between laboratories to assess within laboratory repeatability and between laboratory reproducibility; second, determine the suitability of the circulated solid standards as reference materials for foraminiferal $\mathrm{Mg} / \mathrm{Ca}$ (and $\mathrm{Sr} / \mathrm{Ca}$ ) determinations.

\section{Experimental Design}

[7] This study followed the practice of previous interlaboratory studies [Rosell-Melé et al., 2001; Rosenthal et al., 2004] of maintaining anonymity by assigning random identification numbers to participating laboratories. Note that those numbers are different than the ones given for affiliations. The analytical scheme was constructed with reference to the International Union of Pure and Applied Chemistry (IUPAC) recommendations [Horwitz, 1994, 1995] for interlaboratory comparison studies. Samples of three solid standards were sent to each participant along with a dissolution protocol which participants were requested to follow, with the aim of minimizing effects that could result from different dissolution procedures and enabling the exercise to focus on instrument calibrations. Participants were asked to make replicate dissolutions on the powder samples and to analyze them using the instruments and calibration standards routinely used in their laboratory.

\subsection{Standards}

[8] Three potential solid standards for $\mathrm{Mg} / \mathrm{Ca}$ determinations were identified from the list of commercially available carbonate reference materials compiled by Greaves et al. [2005]; BAM RS3, a calcite CRM (Certified Reference Material) prepared by the Bundesanstalt fur Materialforschung und -prufung, Germany; CMSI 1767, a limestone CRM from the China Metallurgical Standardization Research Institute, Beijing; and ECRM 752-1, a limestone CRM issued by the Bureau of Analyzed Samples Ltd, UK previously examined by Greaves et al. [2005]. The materials were certified for $\mathrm{Mg}$ concentrations but not for $\mathrm{Mg} / \mathrm{Ca}$ ratios at the precision, or sample sizes, relevant to foraminiferal $\mathrm{Mg} / \mathrm{Ca}$ thermometry. Elemental concentrations taken from the certificates of analyses are listed in Table 1 together with calculated element/ calcium ratios.

[9] Propagation of the quoted analytical errors on certified element concentrations gives errors (r.s.d.) on calculated $\mathrm{Mg} / \mathrm{Ca}$ ratios of $2.7 \%$ (BAM RS3), 6.8\% (ECRM 752-1) and 8.3\% (CMSI 1767), insufficiently precise, with the possible exception of BAM RS3, to be directly relevant to foraminiferal $\mathrm{Mg} / \mathrm{Ca}$ determinations. Foraminiferal calcite is composed of extremely pure $(\sim 99 \%) \mathrm{CaCO}_{3}$, equivalent to $39.6 \% \mathrm{Ca}$, with four minor elements $\mathrm{Na}, \mathrm{Mg}, \mathrm{Sr}$ and $\mathrm{F}$ comprising most of the remainder [Lea, 1999] and the relative purity of these materials is shown by their calcium concentrations (Table 1). The presence of $\mathrm{Al}, \mathrm{Fe}, \mathrm{Mn}, \mathrm{Si}$ and $\mathrm{Ti}$ is indicative of other mineral phases. Homogeneity of the solid materials and the contribution to measured $\mathrm{Mg} / \mathrm{Ca}$ from the other mineral phases were investigated in preliminary studies before circulation.

\subsection{Preliminary Studies}

[10] Preliminary tests of homogeneity were performed on standards BAM RS3 and CMSI 1767 at Cambridge and LSCE, respectively, following the 
Table 2. Average $\mathrm{Mg} / \mathrm{Ca}$ Ratios Obtained for CMSI 1767 and BAM RS3 Standards Using Sample Weights in the Range $10-250 \mathrm{mg}$

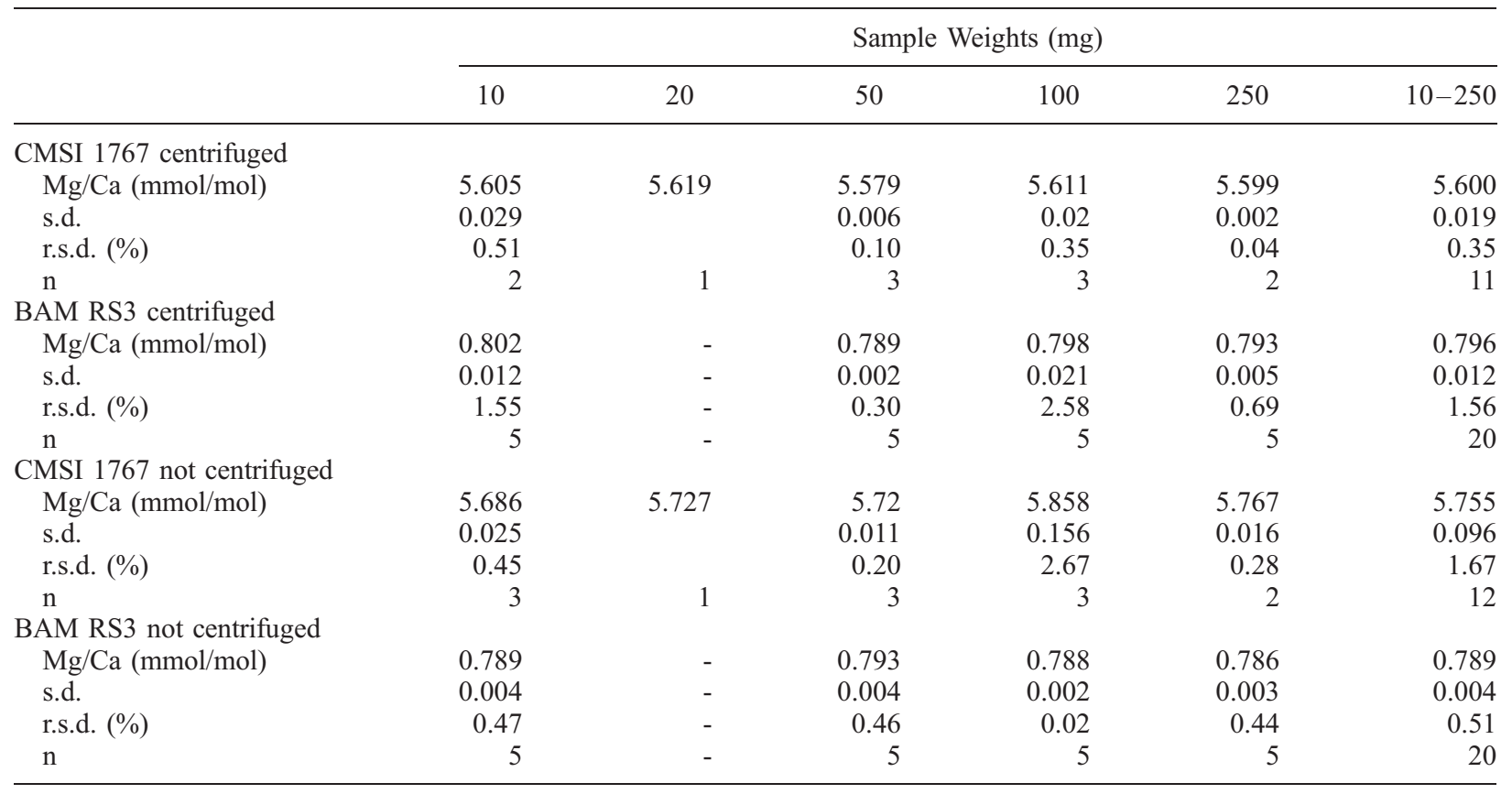

procedure used by Greaves et al. [2005] to test the homogeneity of ECRM 752-1. Replicate aliquots were taken from a single bottle of each standard for a series of weighings in the range 10 to $250 \mathrm{mg}$. Samples were dissolved in $0.075 \mathrm{M} \mathrm{HNO}_{3}$ in acid cleaned HDPE or LDPE bottles, using dissolution volumes in proportion to sample weights to give $\left[\mathrm{Ca}^{2+}\right]$ of $\sim 400 \mu \mathrm{g} / \mathrm{g}$. Solutions were analyzed both with and without centrifugation; two $0.5 \mathrm{~mL}$ aliquots were taken, one centrifuged for $10 \mathrm{~min}$ at $9000 \mathrm{rpm}$ then both diluted to $\left[\mathrm{Ca}^{2+}\right]=40 \mu \mathrm{g} / \mathrm{g}$ $(\mathrm{CMSI} 1767)$ or $\left[\mathrm{Ca}^{2+}\right]=100 \mu \mathrm{g} / \mathrm{g}$ (BAM RS3) and analyzed by ICP-OES. $\mathrm{Mg} / \mathrm{Ca}$ results are reported in Table 2 and illustrated in Figure 1 which shows also $\mathrm{Fe} / \mathrm{Ca}$ measurements in $\mathrm{CMSI}$ 1767.

[11] Results for CMSI 1767 (Figure 1a) demonstrate the contribution to $\mathrm{Mg} / \mathrm{Ca}$ from insoluble noncarbonate minerals within this material which is confirmed by $\mathrm{Fe} / \mathrm{Ca}$ (Figure $1 \mathrm{~b}$ ). Higher and more variable $\mathrm{Mg} / \mathrm{Ca}$ and $\mathrm{Fe} / \mathrm{Ca}$ in noncentrifuged samples, together with consistency between the $\mathrm{Mg} / \mathrm{Ca}$ and $\mathrm{Fe} / \mathrm{Ca}$ data sets in Figures $1 \mathrm{a}$ and $1 \mathrm{~b}$, show the effect of insoluble noncarbonate minerals on homogeneity of this material. Average $\mathrm{Mg} / \mathrm{Ca}$ after centrifuging of $5.60 \mathrm{mmol} / \mathrm{mol}(0.019$ s.d., $0.35 \%$ r.s.d on 11 measurements) confirms the within bottle homogeneity of the readily soluble carbonate material for samples in the 10 to $250 \mathrm{mg}$ weight range. $\mathrm{Fe} / \mathrm{Ca}$ fell to consistent but nonzero values on centrifuging, with average $\mathrm{Fe} / \mathrm{Ca}$ of $0.650 \mathrm{mmol} / \mathrm{mol}(0.018$ s.d., $2.81 \%$ r.s.d on 11 measurements), again demonstrating homogeneity within the readily soluble carbonate matrix.

[12] In contrast, results for BAM RS3 (Figure 1c) show good agreement between centrifuged and noncentrifuged $\mathrm{Mg} / \mathrm{Ca}$ measurements. Average $\mathrm{Mg} / \mathrm{Ca}$ after centrifuging of $0.796 \mathrm{mmol} / \mathrm{mol}$ (0.012 s.d., $1.56 \%$ r.s.d) on 20 measurements was influenced by two high values. Omitting these gave $\mathrm{Mg} / \mathrm{Ca}$ of $0.793 \mathrm{mmol} / \mathrm{mol}(0.008$ s.d., $0.97 \%$ r.s.d) on 18 measurements, compared to noncentrifuged $\mathrm{Mg} / \mathrm{Ca}$ of $0.789 \mathrm{mmol} / \mathrm{mol}(0.004$ s.d., $0.51 \%$ r.s.d) on 20 measurements. $\mathrm{Fe} / \mathrm{Ca}$ in BAM RS3 was consistently low and in most cases below detection, with a maximum of $0.004 \mathrm{mmol} / \mathrm{mol}$ observed. Slightly higher $\mathrm{Mg} / \mathrm{Ca}$ ratios and the greater variability of centrifuged compared to noncentrifuged samples may be a consequence of the additional handling involved and effect of the associated analytical blank on the low $\mathrm{Mg} / \mathrm{Ca}$ of this material.

[13] Measurements of $\mathrm{Sr} / \mathrm{Ca}$ in CMSI 1767 (Figure 1d) revealed a ratio comparable to $\mathrm{Sr} / \mathrm{Ca}$ in foraminiferal calcite and good homogeneity within this material from measurements both with and without centrifugation. Average $\mathrm{Sr} / \mathrm{Ca}$ for samples in the 10 to $250 \mathrm{mg}$ weight range was $1.542 \mathrm{mmol} / \mathrm{mol}(0.010$ s.d., $0.66 \%$ r.s.d) on 11 
a)

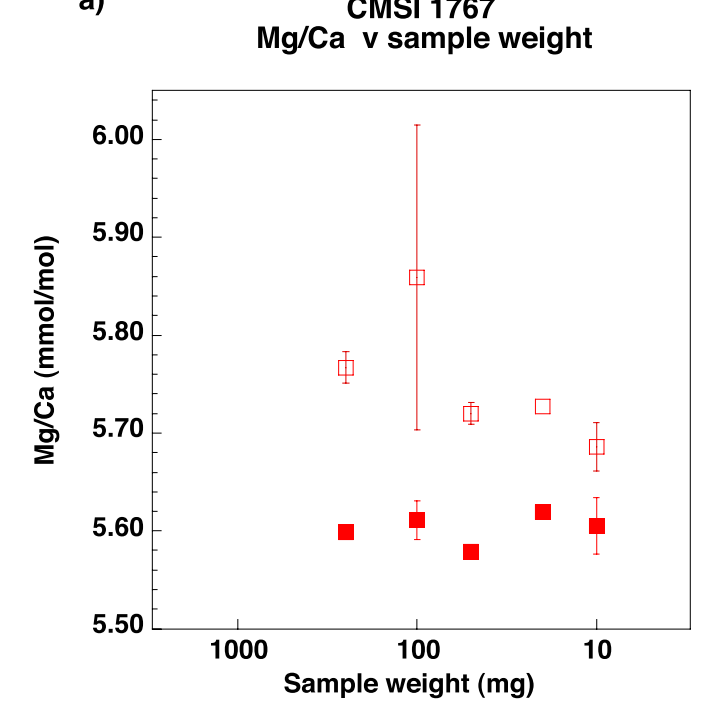

c)

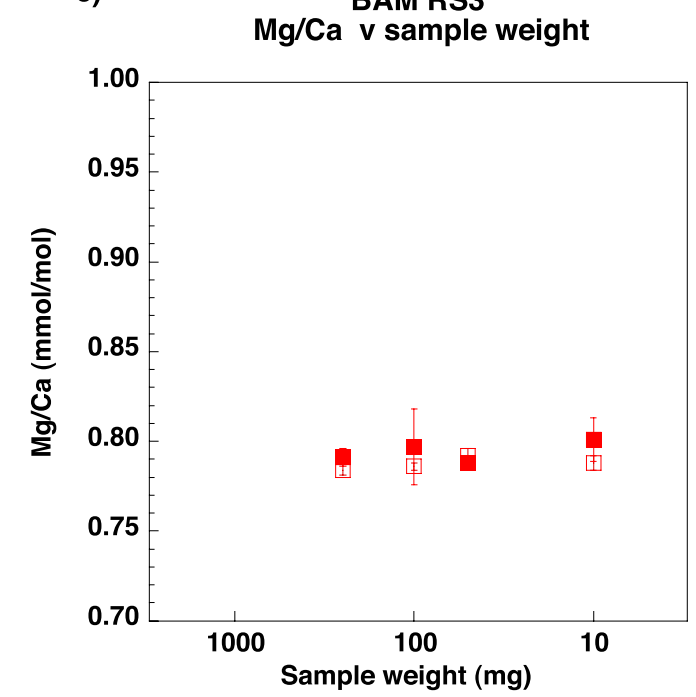

b)

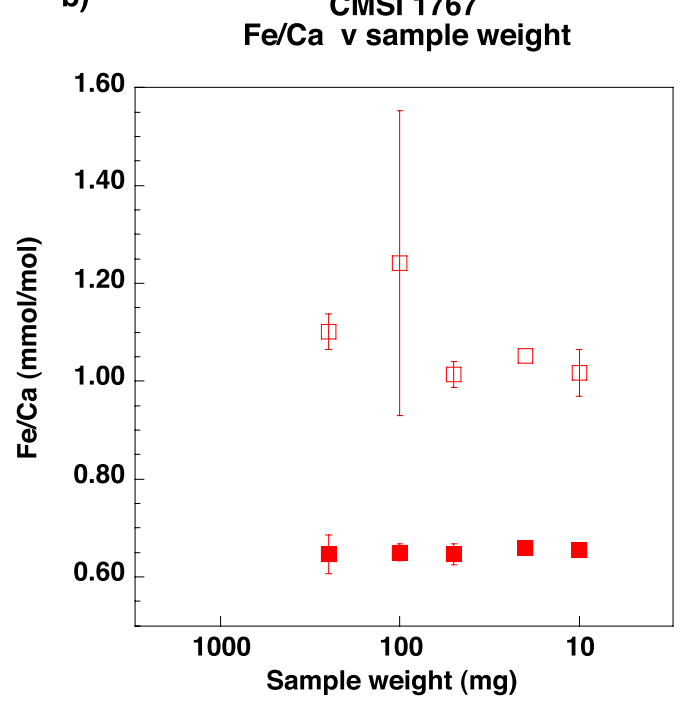

d)

CMSI 1767 Sr/Ca v sample weight

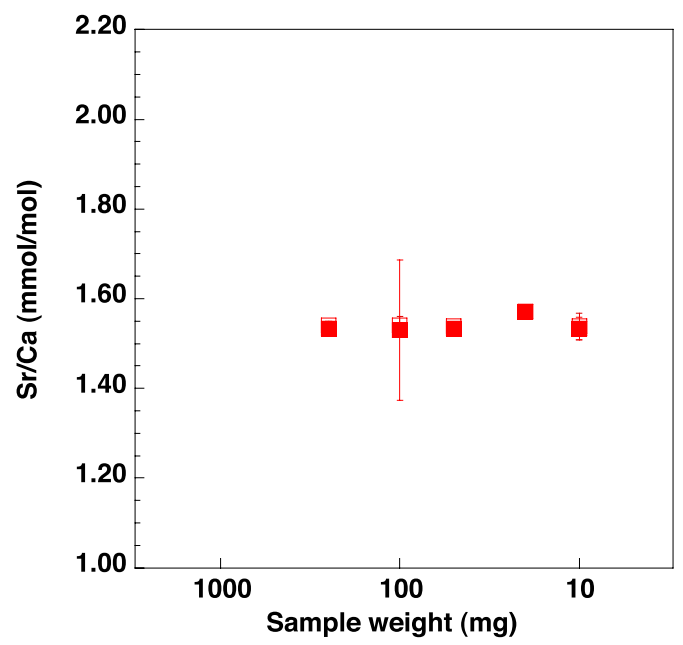

Figure 1. Homogeneity of CMSI 1767 and BAM RS3, measured element ratio versus sample weight: (a) CMSI $1767 \mathrm{Mg} / \mathrm{Ca}$; (b) CMSI $1767 \mathrm{Fe} / \mathrm{Ca}$; (c) BAM RS3 Mg/Ca; and (d) CMSI $1767 \mathrm{Sr} / \mathrm{Ca}$. Open symbols, not centrifuged; solid symbols, centrifuged after dissolution.

measurements after centrifuging and $1.536 \mathrm{mmol} /$ mol (0.013 s.d., $0.86 \%$ r.s.d) on 11 measurements without centrifuging.

[14] The results of the preliminary studies confirmed homogeneity within the carbonate mineral phases of both materials over the range of sample weights used. $\mathrm{Mg} / \mathrm{Ca}$ in $\mathrm{CMSI} 1767$ showed a relationship to $\mathrm{Fe} / \mathrm{Ca}$ similar to that observed previously for ECRM $752-1$ by Greaves et al. [2005], consistent with the quoted concentrations and calculated ratios shown in Table 1 . The similar $\mathrm{Sr} / \mathrm{Ca}$ ratio to foraminiferal calcite found in CMSI 1767 was an added bonus of this material.

\subsection{Sample Preparation and Distribution}

[15] All samples were prepared at LSCE from previously unopened bottles of the standards, containing 80 g CMSI 1767 (without lot number), 100 g BAM RS3 (lot number 41), 100 g ECRM 752-1 (lot number 2133). The standards were mixed well in case of settling during storage then, following the homogeneity tests detailed in the previous section, one gram portions of each standard were weighed into a series of glass sample bottles precleaned by soaking for 24 hours in $10 \%$ $\mathrm{HNO}_{3}$, rinsed with high-purity water and dried for 24 hours. Thus, for each standard, all samples sent 
to laboratories came from the same initial bottle on which homogeneity had been verified.

[16] The participating laboratories were each sent one subsample bottle of each of the three standards and requested to perform replicate analyses as described in section 2.4 except that as a check on homogeneity of the materials after subsampling, one laboratory (25) was sent five subsample bottles of each standard and asked to make a single determination from each subsample.

\subsection{Protocol for Dissolution}

[17] The primary objective of this $\mathrm{Mg} / \mathrm{Ca}$ interlaboratory comparison was to check instrumental calibrations between laboratories and a dissolution protocol was devised with the aim of minimizing effects from noncarbonate mineral phases in the standards and from laboratories following different procedures. Participants were requested to follow the following procedure: (1) number of replicate dissolutions, 6 per standard; (2) sample weight, $50 \mathrm{mg}$; (3) dissolution volume, $50 \mathrm{~mL}$; (4) dissolution acid, $0.075 \mathrm{M} \mathrm{HNO}_{3}$ (or as routinely used in their laboratory); (5) samples to be dissolved and analyzed on the same day; (6) a blank solution to be included; (7) solutions to be analyzed both with and without centrifuging, and (8) samples to be diluted as required for the usual instrumental procedures of each laboratory.

[18] It was intended that after initial bottle cleaning and reagent preparation, the dissolution and analyses could be completed in a single day of laboratory and instrument time. Laboratories performing analyses in solution were asked to follow, as far as possible, the protocol supplied. Laboratories doing analyses not in solution were free to investigate the materials as they saw fit. In addition to results for $\mathrm{Mg} / \mathrm{Ca}$, participants were asked to provide data for $\mathrm{Sr} / \mathrm{Ca}$ and for elements indicating silicate contamination, such as $\mathrm{Al}, \mathrm{Fe}, \mathrm{Mn}, \mathrm{Si}$, Ti, depending on those typically measured in their laboratory. The participants were provided with the approximate $\mathrm{Mg} / \mathrm{Ca}$ ratios of the three materials calculated from quoted element concentrations (Table 1), but were not informed of the $\mathrm{Sr} / \mathrm{Ca}$ ratio found for CMSI 1767 in the preliminary studies, making CMSI 1767 a blind sample for the determination of $\mathrm{Sr} / \mathrm{Ca}$.

\subsection{Reporting of the Results}

[19] A file containing spreadsheets for returning experimental information and results using a template for each material was sent with the protocol.
On return the files were first screened to ensure that no laboratory or personal information had been included and that results were identified only by laboratory numbers before being passed to the coordinators. In this way anonymity was preserved both among participants and the coordinators when examining data. The results were tabulated in a common format by the coordinators to give a single value for each sample of material dissolved and analyzed before calculating the mean of replicate analyses by each laboratory, i.e., where some laboratories had made multiple determinations on a single dissolution of material these were combined to give a single result per analysis. The complete set of results, individual analyses, means and standard deviations of replicate dissolutions by each laboratory are presented in auxiliary material ${ }^{1}$ Tables S1-S3. Statistical analysis of the data followed the protocol of Horwitz [1995] and the guidelines of AOAC International [2006]. One of the criteria specified in this protocol is that only valid data should be subject to statistical analysis. In the context of this exercise, valid $\mathrm{Mg} / \mathrm{Ca}$ data are those where significant influences from other noncarbonate phases can be excluded and therefore, results for each of the three materials were examined critically, as described in section 3, to identify nonvalid data on analytical grounds as preferable to relying on statistical tests alone [Horwitz, 1995].

\subsection{Outlier Testing}

[20] The outcome of outlier tests depends to a large extent on the tests themselves and how they are applied. Statistical tests can identify observations which differ from the majority of others according to the rules applied, but cannot give a reason. A decision to label data as outliers should reflect scientific experience as much as the application of a statistical rule [Horwitz, 1995; Davies, 1988; Meier and Zünd, 2000]. The following tests were applied with these caveats in mind.

[21] Measurements identified as outliers for analytical reasons by individual laboratories were first excluded, then a three-sigma test (three standard deviation test) was applied to each set of data for a standard and laboratory. Data superior to the mean plus 3 sigma, or inferior to the mean minus 3 sigma, were excluded and means recalculated before data were submitted to outlier testing using Cochran and Grubbs tests [Horwitz, 1995; AOAC International, 2006]. The Cochran test is used to

${ }^{1}$ Auxiliary materials are available at $\mathrm{ftp} / / \mathrm{ftp}$. agu.org/apend/gc/ 2008 GC001974. 
identify sets of results showing significantly greater variability among replicate (within-laboratory) analyses than the other laboratories for a given material. This test was applied as a 1-tail test at a probability value of $2.5 \%$. To apply this test, we computed the within-laboratory variance for each laboratory and divided the largest of these by the sum of the variances. The resulting quotient is the Cochran statistic which indicates the presence of a removable outlier if the critical value listed in the Cochran table for $\mathrm{P}=2.5 \%$ is exceeded. The Grubbs test is used to identify laboratories with extreme averages. This test was applied in the following order: single value test (2-tail; $\mathrm{P}=$ $2.5 \%$ ); then if no outlier was found a pair value test was applied ( 2 values at the highest end and 2 values at the lowest end; then 2 values, one at each end, at an overall $\mathrm{P}=2.5 \%$ ).

\subsection{Statistical Data Treatment}

[22] To perform statistical data treatment, we followed the International Standardization Organization [1994], which is based on the analysis of variance (ANOVA) method. We applied a statistical scheme equivalent to that commonly used in interlaboratory analytical studies [Nilsson et al., 1997; Rosell-Melé et al., 2001; Rosenthal et al., 2004]. Summary statistics $\left(\mathrm{S}_{\mathrm{r}}, \mathrm{S}_{\mathrm{R}}, \mathrm{RSD}_{\mathrm{r}}, \mathrm{RSD}_{\mathrm{R}}\right)$ were calculated for the average ratios and overall method precisions for each of the three standards. In this scheme, we focused on: the single-analyst standard deviation $\left(\mathrm{S}_{\mathrm{r}}\right.$, repeatability), the precision associated with the performance of an individual laboratory, the overall standard deviation $\left(\mathrm{S}_{\mathrm{R}}\right.$, reproducibility), the precision associated with measurements generated by a group of laboratories. The repeatability $\mathrm{RSD}_{\mathrm{r}}$ is determined from the repeatability standard deviation $\left(\mathrm{S}_{\mathrm{r}}\right)$ and the average concentration for a particular test sample, giving an indication of the intralaboratory precision. The reproducibility $\mathrm{RSD}_{\mathrm{R}}$, determined from the reproducibility standard deviation $\left(\mathrm{S}_{\mathrm{R}}\right)$ and the average concentration of a particular test sample, gives an indication of the interlaboratory method precision. Equating $\mathrm{S}_{\mathrm{R}}$ to measurement uncertainty and assuming a normal distribution gives a confidence interval of $\sim 67 \%$ that the result plus and minus $S_{R}$ will encompass the "true" value. Multiplying $S_{R}$ by a coverage factor of 2 gives the "expanded measurement uncertainty" with a confidence interval of $\sim 95 \%$ that the result plus and minus $2 S_{R}$ will encompass the "true" value. The reproducibility limit (R) or repeatability limit (r) is the value less than or equal to which the absolute difference between two results obtained under reproducibility or repeatability conditions is expected to be with a probability of $95 \%$. For a normal distribution $\mathrm{r}=$ $2.8 \mathrm{~S}_{\mathrm{r}}$ and $\mathrm{R}=2.8 \mathrm{~S}_{\mathrm{R}}$.

\section{Results and Discussion}

[23] The twenty-five participating laboratories each returned results of $\mathrm{Mg} / \mathrm{Ca}$ determinations on one or more of the three materials, twenty-four laboratories performed analyses after dissolution and one used a flow through method [Benway et al., 2003]. Instrumental determinations were by either inductively coupled plasma optical emission spectrophotometry (ICP-OES), used by sixteen laboratories or inductively coupled plasma mass spectrometry (ICP-MS), by nine laboratories. The supplied experimental protocol was followed by most of the participants although four laboratories used significantly smaller quantities of solid material (10$20 \mathrm{mg}$ ) than the $50 \mathrm{mg}$ proposed. Homogeneity implications of using small samples are assessed during discussion of the results. Twenty-two laboratories returned results of $\mathrm{Sr} / \mathrm{Ca}$ determinations in addition to $\mathrm{Mg} / \mathrm{Ca}$. Element ratios frequently used as contamination indicators [e.g., Barker et al., 2003; Lea et al., 2005] were returned by the laboratories as follows; $\mathrm{Mn} / \mathrm{Ca}$ by thirteen laboratories, $\mathrm{Fe} / \mathrm{Ca}$ by eight, $\mathrm{Al} / \mathrm{Ca}$ by seven, $\mathrm{Ti} / \mathrm{Ca}$ by five and $\mathrm{Si} / \mathrm{Ca}$ by two laboratories. Data for other trace element ratios including $\mathrm{Ba} / \mathrm{Ca}, \mathrm{Cd} / \mathrm{Ca}, \mathrm{Nd} /$ $\mathrm{Ca}, \mathrm{U} / \mathrm{Ca}$ and $\mathrm{Zn} / \mathrm{Ca}$ were returned by one laboratory or more with a maximum of five participants returning results of $\mathrm{Ba} / \mathrm{Ca}$ determinations. Details of the procedures used and number of results reported for each material and element ratio measured are given in auxiliary material Tables S1-S3.

[24] Results for $\mathrm{Mg} / \mathrm{Ca}, \mathrm{Sr} / \mathrm{Ca}$ and element ratios measured to indicate possible contamination from noncarbonate phases are presented and discussed for each of the three materials separately in sections 3.1 to 3.3. Comparisons between the three materials are made in section 3.4. Analytical details, individual results, means and statistics are presented in detail for each material in auxiliary material Tables S1S3. Results for other trace metal ratios which do not relate directly to $\mathrm{Mg} / \mathrm{Ca}$ are included in auxiliary material Tables $\mathrm{S} 1-\mathrm{S} 3$.

\subsection{BAM RS3}

[25] $\mathrm{Mg} / \mathrm{Ca}$ was determined in BAM RS3 by all twenty-five participants on samples without centrifugation and by twenty-one laboratories after centri- 
fuging solutions. Results are shown in Table 3 and mean values plotted for each laboratory in Figure 2, in ascending order of uncentrifuged values, using data before statistical rejection. A single data point, flagged as contaminated by a laboratory (25) was excluded from results after centrifugation. Error bars plotted in Figure 2 are \pm 2 standard errors on the mean $(=2 * \mathrm{SD} / \sqrt{ } \mathrm{n})$ to allow for the different number of determinations by laboratories. Histograms of the individual measurements, for solutions after centrifuging, are presented in Figure 3, showing the distribution of results among laboratories (Figure 3a) and comparing results obtained by the two instrumental techniques (Figure 3b).

[26] Within laboratory standard deviations, including all results except the determination identified as contaminated, average $0.010 \mathrm{mmol} / \mathrm{mol}$ (centrifuged) and $0.013 \mathrm{mmol} / \mathrm{mol}$ (not centrifuged) which, because of the low $\mathrm{Mg} / \mathrm{Ca}$ in this material, translate into average intralaboratory precisions of $1.33 \%$ and $1.64 \%$, respectively. The average precisions conceal a wide range in intralaboratory repeatability, from $0.17 \%$ to $4.31 \%$ for determinations after centrifuging and $0.12 \%$ to $7.58 \%$ (or $5.95 \%$ excluding the flow through technique, lab 29), for determinations without centrifuging (Table 3).

[27] Between laboratory precisions, again taking all results for $\mathrm{Mg} / \mathrm{Ca}$ determinations in BAM RS3, are approximately four times worse than average within laboratory precisions at $5.4 \%$ and $5.6 \%$ for centrifuged and not centrifuged results, respectively. With the exception of laboratory 18 and to a lesser extent laboratories 3 and 19, the results with and without centrifuging are in agreement, giving overall mean $\mathrm{Mg} / \mathrm{Ca}$, before statistical analysis, from all laboratories of $0.775 \mathrm{mmol} / \mathrm{mol}(0.043$ s.d., $5.57 \%$ r.s.d) on 25 determinations without centrifuging and $0.784 \mathrm{mmol} / \mathrm{mol}(0.043$ s.d., $5.44 \%$ r.s.d) on 21 determinations after centrifuging (Table 3).

[28] The range of the results shown in Figures 2 and 3 could be caused by a number of analytical or geochemical factors and these are investigated here before discussing statistical analysis of the data. Three laboratories $(13,17,26)$ used small $(10 \mathrm{mg})$ samples for dissolution. Laboratory 13 performed analyses without centrifugation only but results of centrifuged and not centrifuged determinations from laboratories 17 and 26 are in close agreement, suggesting that homogeneity of the solid material when using $10 \mathrm{mg}$ is not a major factor, in agreement with the preliminary homogeneity study described in section 2.2. If results for these laboratories, and also lab 29 which used the flow through procedure, are omitted, the between laboratory reproducibility is improved slightly but with little effect on the mean values obtained (Table 3), simply because results from laboratories 17 and 26 were above average, while those from laboratories 29 and 13 were below.

[29] The potential for magnesium contamination in analyses of BAM RS3 is significant because of its low $\mathrm{Mg} / \mathrm{Ca}$ ratio. The dissolution protocol was designed to minimize the effect of the Mg blank during dissolution by producing high initial concentrations. Most laboratories adhered to this (Table 3) with a minimum initial $\mathrm{Ca}$ concentration, used by laboratory 13, of $120 \mu \mathrm{g} / \mathrm{g}$. Calcium concentrations of the final instrumental determinations cover a very wide range from 1 to $>400 \mu \mathrm{g} / \mathrm{g}$, some laboratories diluting solutions before running while others ran concentrates without dilution. Although the possibility of $\mathrm{Mg}$ contamination can never be excluded and it may contribute to within laboratory repeatability, there is no apparent relationship between the concentrations used for final determination (Table 3) and the $\mathrm{Mg} / \mathrm{Ca}$ results shown in Figure 2.

[30] Laboratories where other element ratios were determined, including $\mathrm{Al} / \mathrm{Ca}, \mathrm{Fe} / \mathrm{Ca}, \mathrm{Mn} / \mathrm{Ca}, \mathrm{Si} / \mathrm{Ca}$, $\mathrm{Ti} / \mathrm{Ca}$, as indicators of contamination by noncarbonate minerals found very low values in BAM RS3, confirming the results of the preliminary study and anticipated from the quoted element concentrations shown in Table 1. Similarly, $\mathrm{Sr} / \mathrm{Ca}$ in this material was confirmed to be very low at approximately $0.18 \mathrm{mmol} / \mathrm{mol}$, from both centrifuged and noncentrifuged determinations, much lower than relevant to the typical $\mathrm{Sr} / \mathrm{Ca}$ range of $1.0-1.5 \mathrm{mmol} / \mathrm{mol}$ found in foraminiferal calcite. Results are included in the auxiliary material.

[31] Statistical analysis using the Cochran test rejects results from laboratories 19,29 and 33 for analyses without centrifuging, and from laboratories 6, 18 and 22 (and 29) for analyses after centrifuging, on the basis of the within laboratory variance (Table 3 and Figure 2). After exclusion of results identified by the Cochran test, no outlying average values were found on application of the Grubbs test. The results after statistical data rejection are $\mathrm{Mg} / \mathrm{Ca}=0.791 \mathrm{mmol} / \mathrm{mol}(0.030$ s.d., $3.79 \%$ r.s.d) on 18 determinations after centrifuging and $\mathrm{Mg} / \mathrm{Ca}=0.777 \mathrm{mmol} / \mathrm{mol}(0.043$ s.d., $5.53 \%$ r.s.d) on 22 determinations without centri- 
Table 3. Results From Each Laboratory for the Determination of $\mathrm{Mg} / \mathrm{Ca}$ in $\mathrm{BAM} \mathrm{RS} 3$

\begin{tabular}{|c|c|c|c|c|c|c|c|c|c|c|c|c|c|c|c|}
\hline \multirow[b]{2}{*}{ Lab ID } & \multicolumn{3}{|c|}{ Dissolution } & \multicolumn{6}{|c|}{ Centrifuged Solutions } & \multicolumn{6}{|c|}{ Not Centrifuged } \\
\hline & $\begin{array}{c}\text { Wt } \\
\text { Solid } \\
(\mathrm{mg})\end{array}$ & $\begin{array}{l}\text { Volume } \\
\text { (mL) }\end{array}$ & $\begin{array}{c}{[\mathrm{Ca}]} \\
(\mu \mathrm{g} / \mathrm{g})\end{array}$ & $\begin{array}{c}{[\mathrm{Ca}]} \\
(\mu \mathrm{g} / \mathrm{g})\end{array}$ & $\mathrm{Mg} / \mathrm{Ca}$ & SD & $\begin{array}{l}\text { r.s.d. } \\
(\%)\end{array}$ & $2 \mathrm{SE}$ & $\mathrm{n}$ & $\begin{array}{c}{[\mathrm{Ca}]} \\
(\mu \mathrm{g} / \mathrm{g})\end{array}$ & $\mathrm{Mg} / \mathrm{Ca}$ & SD & $\begin{array}{l}\text { r.s.d. } \\
(\%)\end{array}$ & $2 \mathrm{SE}$ & $\mathrm{n}$ \\
\hline 1 & 50 & 40 & 500 & 100 & 0.801 & 0.010 & 1.24 & 0.008 & 6 & 100 & 0.800 & 0.012 & 1.45 & 0.010 & 6 \\
\hline 2 & 50 & 50 & 400 & & & & & & & 430 & 0.785 & 0.012 & 1.56 & 0.010 & 6 \\
\hline 3 & 50 & 50 & 400 & 360 & 0.813 & 0.005 & 0.63 & 0.004 & 6 & 400 & 0.842 & 0.004 & 0.49 & 0.003 & 6 \\
\hline 4 & $20-50$ & $20-50$ & 400 & 40 & 0.770 & 0.011 & 1.37 & 0.009 & 6 & 40 & 0.765 & 0.008 & 1.01 & 0.006 & 6 \\
\hline 5 & 50 & 50 & 400 & 50 & 0.804 & 0.017 & 2.10 & 0.015 & 5 & 50 & 0.814 & 0.018 & 2.16 & 0.016 & 5 \\
\hline 6 & 50 & 50 & 400 & 20 & 0.747 & 0.022 & 2.95 & 0.018 & 6 & 20 & 0.743 & 0.008 & 1.12 & 0.007 & 6 \\
\hline 7 & 50 & 50 & 400 & & & & & & & 40 & 0.751 & 0.005 & 0.66 & 0.004 & 6 \\
\hline 12 & 50 & 50 & 400 & 40 & 0.782 & 0.003 & 0.40 & 0.003 & 6 & 40 & 0.774 & 0.005 & 0.65 & 0.004 & 6 \\
\hline 13 & 10 & 35 & 120 & & & & & & & 120 & 0.738 & 0.002 & 0.24 & 0.001 & 6 \\
\hline 14 & 50 & 50 & 400 & 160 & 0.777 & 0.004 & 0.48 & 0.003 & 6 & 160 & 0.780 & 0.005 & 0.67 & 0.004 & 6 \\
\hline 16 & 50 & 50 & 400 & 80 & 0.792 & 0.017 & 2.09 & 0.014 & 6 & 80 & 0.790 & 0.007 & 0.89 & 0.006 & 6 \\
\hline 17 & 10 & 10 & 400 & 80 & 0.848 & 0.004 & 0.45 & 0.003 & 6 & 80 & 0.847 & 0.007 & 0.88 & 0.006 & 6 \\
\hline 18 & 50 & 50 & 400 & 50 & 0.834 & 0.036 & 4.31 & 0.029 & 6 & 50 & 0.726 & 0.007 & 1.01 & 0.006 & 6 \\
\hline 19 & 50 & 50 & 400 & 60 & 0.798 & 0.011 & 1.42 & 0.009 & 6 & 60 & 0.775 & 0.038 & 4.88 & 0.031 & 6 \\
\hline 20 & 50 & 50 & 400 & 70 & 0.824 & 0.001 & 0.17 & 0.002 & 3 & 70 & 0.823 & 0.001 & 0.12 & 0.001 & 6 \\
\hline 21 & 50 & 50 & 400 & 80 & 0.787 & 0.004 & 0.49 & 0.003 & 6 & 80 & 0.787 & 0.008 & 0.98 & 0.006 & 6 \\
\hline 22 & 50 & 50 & 400 & 50 & 0.656 & 0.023 & 3.53 & 0.019 & 6 & 50 & 0.671 & 0.008 & 1.20 & 0.007 & 6 \\
\hline 23 & 50 & 50 & 400 & 20 & 0.741 & 0.007 & 1.00 & 0.006 & 6 & 20 & 0.749 & 0.009 & 1.21 & 0.007 & 6 \\
\hline 24 & 50 & 50 & 400 & 4 & 0.810 & 0.005 & 0.57 & 0.004 & 6 & 4 & 0.809 & 0.011 & 1.34 & 0.009 & 6 \\
\hline 25 & 50 & 50 & 400 & 100 & 0.784 & 0.002 & 0.24 & 0.002 & 4 & 100 & 0.783 & 0.003 & 0.44 & 0.003 & 5 \\
\hline 26 & 10 & 5 & 800 & 160 & 0.823 & 0.004 & 0.47 & 0.003 & 6 & 160 & 0.832 & 0.012 & 1.42 & 0.010 & 6 \\
\hline 29 & & & & & & & & & & & 0.705 & 0.053 & 7.58 & 0.062 & 3 \\
\hline 30 & 50 & 50 & 400 & 100 & 0.725 & 0.007 & 0.93 & 0.007 & 4 & 100 & 0.726 & 0.015 & 2.04 & 0.012 & 6 \\
\hline 31 & $40-68$ & 50 & $330-530$ & 50 & 0.757 & 0.009 & 1.17 & 0.007 & 6 & 50 & 0.756 & 0.008 & 1.12 & 0.007 & 6 \\
\hline 33 & 50 & 50 & 400 & 1 & 0.800 & 0.016 & 1.94 & 0.013 & 6 & 1 & 0.807 & 0.048 & 5.95 & 0.039 & 6 \\
\hline \multicolumn{16}{|l|}{ All results } \\
\hline Mean (mmol/mol) & & & & & 0.784 & 0.010 & 1.33 & 0.009 & & & 0.775 & 0.013 & 1.64 & 0.011 & \\
\hline s.d. & & & & & 0.043 & & & & & & 0.043 & & & & \\
\hline r.s.d. (\%) & & & & & 5.44 & & & & & & 5.57 & & & & \\
\hline $\mathrm{n}$ & & & & & 21 & & & & & & 25 & & & & \\
\hline \multicolumn{16}{|l|}{$>10 \mathrm{mg}$ powder } \\
\hline Mean & & & & & 0.779 & 0.011 & 1.42 & 0.009 & & & 0.774 & 0.011 & 1.47 & 0.009 & \\
\hline s.d. & & & & & 0.041 & & & & & & 0.039 & & & & \\
\hline r.s.d. (\%) & & & & & 5.28 & & & & & & 5.01 & & & & \\
\hline $\mathrm{n}$ & & & & & 19 & & & & & & 21 & & & & \\
\hline \multicolumn{16}{|c|}{$\begin{array}{l}\text { After statistical analysis } \\
\text { for outliers }\end{array}$} \\
\hline Mean & & & & & 0.791 & 0.008 & 0.95 & 0.006 & & & 0.777 & 0.008 & 1.03 & 0.007 & \\
\hline s.d. & & & & & 0.030 & & & & & & 0.043 & & & & \\
\hline r.s.d. (\%) & & & & & 3.79 & & & & & & 5.53 & & & & \\
\hline $\mathrm{n}$ & & & & & 18 & & & & & & 22 & & & & \\
\hline
\end{tabular}

fuging (Table 3). Following statistical data rejection, results obtained by ICPMS are indistinguishable from those obtained by ICP-OES (Figure 3b), in agreement with the conclusions of a recent study [Andreasen et al., 2006].

[32] The mean values obtained from both noncentrifuged and centrifuged determinations, either with or without statistical data rejection, are close to the $\mathrm{Mg} / \mathrm{Ca}$ ratio of $0.8 \mathrm{mmol} / \mathrm{mol}$ calculated from the certified concentrations (Table 1). The material circulated showed good homogeneity and purity and is a valuable reference material for $\mathrm{Mg} / \mathrm{Ca}$ determinations. However, the spread of results shown in Figure 2 and the associated reproducibility statistics highlight the discrepancy between calibration standards used by laboratories. Results of the analysis of variance (ANOVA) are presented and discussed with those from the other two materials in section 3.4.

\subsection{ECRM 752-1}

[33] Results for $\mathrm{Mg} / \mathrm{Ca}$ in ECRM 752-1 are presented in Table 4. Twenty-four laboratories analyzed the material without centrifugation and 


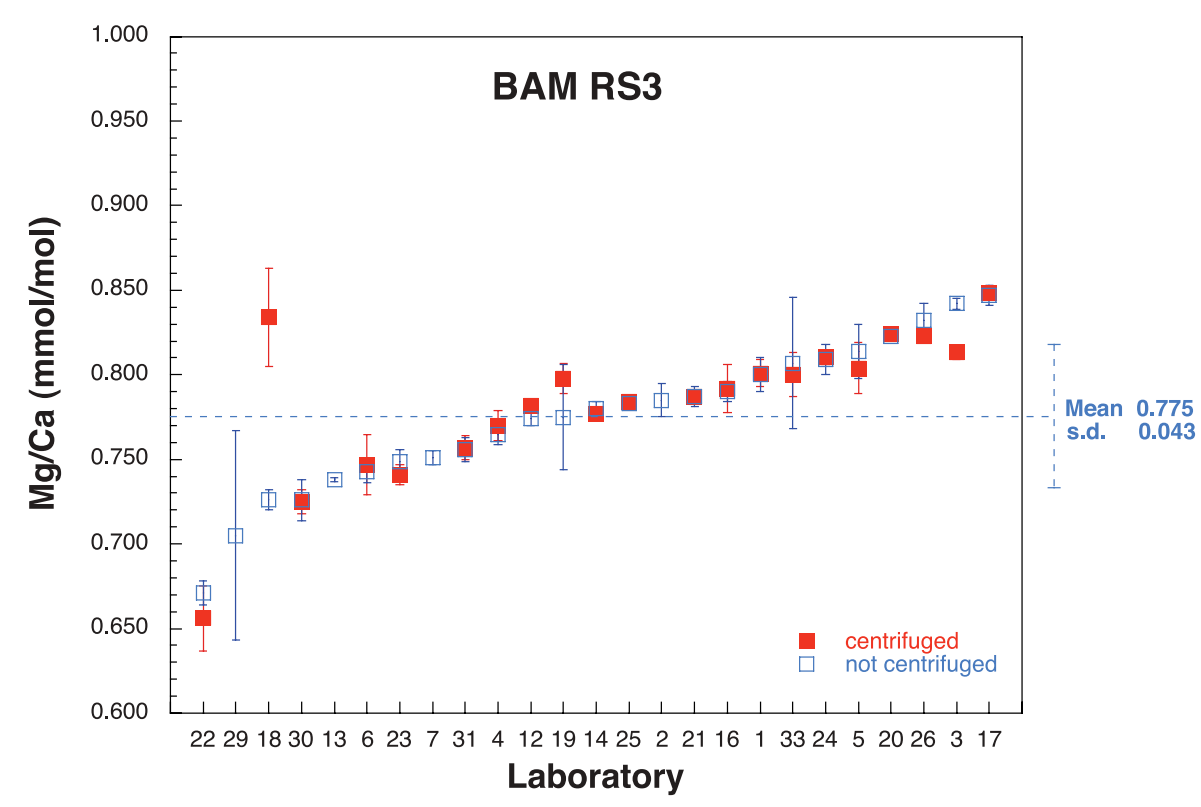

Figure 2. BAM RS3. Mg/Ca means of results from each laboratory, without statistical rejection. Open symbols, not centrifuged; solid symbols, centrifuged after dissolution. Error bars are \pm 2 std errors on the mean from each laboratory. Interlaboratory mean and standard deviation before statistical rejection shown for not centrifuged analyses.

twenty-one laboratories after centrifuging solutions. The means were calculated using all data submitted by the participants except for one data point flagged as an outlier in results after centrifugation by the participating laboratory (24) and one data point excluded from results before centrifugation (Lab 5) on the basis that it was more than three standard deviations from the mean. The complete data set is presented in auxiliary material Tables $\mathrm{S} 1-$ S3. Mean values obtained by each laboratory for this material are plotted in Figure 4a in ascending order of centrifuged values and individual measurements are shown in histograms in Figures 5a and $5 b$.

[34] Within laboratory standard deviations were similar for analyses both with and without centrifuging, averaging 0.026 and $0.027 \mathrm{mmol} / \mathrm{mol}$, respectively, and equivalent to within laboratory precisions of $0.70 \%$ r.s.d. for this material. As found for BAM RS3, within laboratory precisions cover a wide range, from 0.18 to $1.47 \%$ for determinations after centrifuging solutions and 0.16 to $2.31 \%$ for determinations without centrifuging (Table 4). The between laboratory precisions are approximately 3.5 times worse than within laboratory precision, again reflecting the situation found for BAM RS3.

[35] It was demonstrated previously [Greaves et al., 2005] that silicate mineral phases within this material must be removed in order to obtain reproducible $\mathrm{Mg} / \mathrm{Ca}$ results from the carbonate. Eight laboratories measured $\mathrm{Fe} / \mathrm{Ca}$ as an indicator of silicate contamination (Figure $4 \mathrm{~b}$ ) and seven measured $\mathrm{Al} / \mathrm{Ca}$ (Figure 4c). Fewer participants determined $\mathrm{Si} / \mathrm{Ca}$ or $\mathrm{Ti} / \mathrm{Ca}$ while thirteen laboratories returned $\mathrm{Mn} / \mathrm{Ca}$ measurements. The results are included in the complete data set in auxiliary material Tables S1-S3. The effect of silicate contamination on noncentrifuged $\mathrm{Mg} / \mathrm{Ca}$ determinations is evident in Figure $4 \mathrm{a}$ and confirmed, where available, by $\mathrm{Fe} / \mathrm{Ca}$ and $\mathrm{Al} / \mathrm{Ca}$ (Figures $4 \mathrm{~b}$ and $4 \mathrm{c}$ ). $\mathrm{Fe} / \mathrm{Ca}$ falls to approximately $0.07 \mathrm{mmol} / \mathrm{mol}$ on centrifuging and $\mathrm{Al} / \mathrm{Ca}$ to $<0.3 \mathrm{mmol} / \mathrm{mol}$, below or very close to detection by ICP-OES. Where laboratories did not determine either $\mathrm{Fe} / \mathrm{Ca}$ or $\mathrm{Al} /$ $\mathrm{Ca}$ it must be assumed that the centrifugation procedure used was adequate to remove any suspended undissolved silicate minerals. ICP-MS results for $\mathrm{Al} / \mathrm{Ca}$ were returned by laboratory 29 using the flow through method [Benway et al., 2003] where a mean $\mathrm{Al} / \mathrm{Ca}$ of $0.17 \mathrm{mmol} / \mathrm{mol}$ was found. This is close to the average $\mathrm{Al} / \mathrm{Ca}$ of $0.13 \mathrm{mmol} / \mathrm{mol}$ returned by three laboratories after centrifugation (Figure 4c) and, except for one determination (Lab 20), much lower than the average $\mathrm{Al} / \mathrm{Ca}$ of $0.65 \mathrm{mmol} / \mathrm{mol}$ found without centrifugation. It would appear from this evidence to be appropriate to include results by the flow through method with centrifuged rather than noncentrifuged data. 
a)

BAM RS3 (centrifuged) individual Mg/Ca measurements

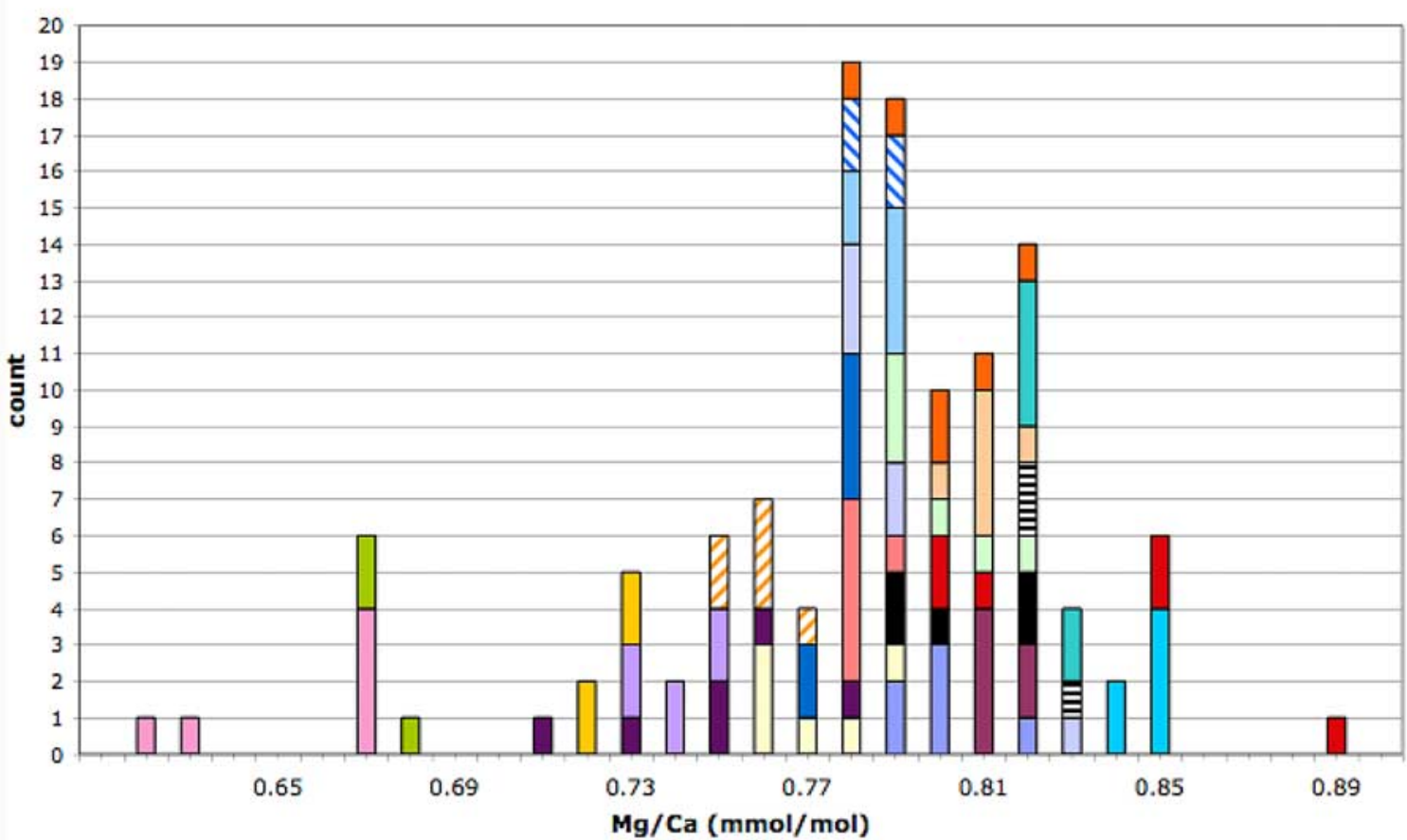

\section{b)}

\section{ICP-MS and ICP-OES Mg/Ca measurements} of BAM RS3 (centrifuged)

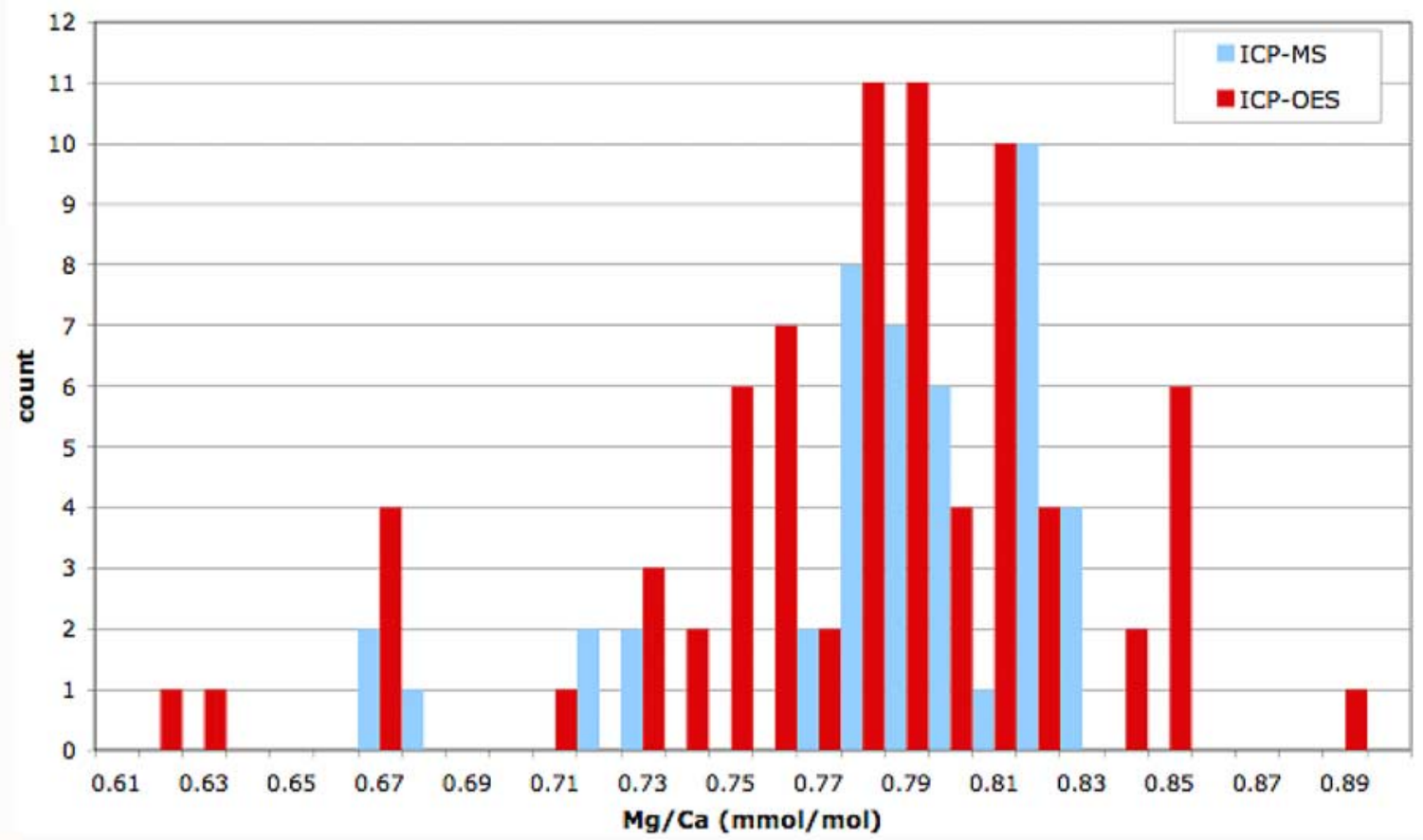

Figure 3. BAM RS3. Histograms of $\mathrm{Mg} / \mathrm{Ca}$ results from each laboratory for solutions after centrifuging: (a) individual measurements from each laboratory and (b) comparison of results by ICP-MS and ICP-OES. 
Table 4. Results From Each Laboratory for the Determination of $\mathrm{Mg} / \mathrm{Ca}$ in ECRM 752-1

\begin{tabular}{|c|c|c|c|c|c|c|c|c|c|c|c|c|c|c|c|}
\hline \multirow[b]{2}{*}{ Lab ID } & \multicolumn{3}{|c|}{ Dissolution } & \multicolumn{6}{|c|}{ Centrifuged Solutions } & \multicolumn{6}{|c|}{ Not Centrifuged } \\
\hline & $\begin{array}{c}\text { Wt } \\
\text { Solid } \\
\text { (mg) }\end{array}$ & $\begin{array}{l}\text { Volume } \\
\text { (mL) }\end{array}$ & $\begin{array}{c}{[\mathrm{Ca}]} \\
(\mu \mathrm{g} / \mathrm{g})\end{array}$ & $\begin{array}{c}{[\mathrm{Ca}]} \\
(\mu \mathrm{g} / \mathrm{g})\end{array}$ & $\mathrm{Mg} / \mathrm{Ca}$ & SD & $\begin{array}{l}\text { r.s.d. } \\
(\%)\end{array}$ & $2 \mathrm{SE}$ & $\mathrm{n}$ & $\begin{array}{c}{[\mathrm{Ca}]} \\
(\mu \mathrm{g} / \mathrm{g})\end{array}$ & $\mathrm{Mg} / \mathrm{Ca}$ & SD & $\begin{array}{c}\text { r.s.d. } \\
(\%)\end{array}$ & $2 \mathrm{SE}$ & $\mathrm{n}$ \\
\hline 1 & 50 & 40 & 500 & 100 & 3.677 & 0.032 & 0.87 & 0.026 & 6 & & & & & & \\
\hline 2 & 50 & 50 & 400 & 400 & & & & & & 430 & 3.983 & 0.029 & 0.72 & 0.023 & 6 \\
\hline 3 & 50 & 50 & 400 & 400 & 3.818 & 0.013 & 0.35 & 0.011 & 6 & 400 & 4.013 & 0.023 & 0.58 & 0.019 & 6 \\
\hline 4 & 23 & 23 & 400 & 40 & 3.718 & 0.017 & 0.45 & 0.019 & 3 & 40 & 3.790 & 0.010 & 0.25 & 0.011 & 3 \\
\hline 5 & 50 & 50 & 400 & 50 & 3.761 & 0.044 & 1.18 & 0.036 & 6 & 50 & 3.796 & 0.033 & 0.86 & 0.029 & 5 \\
\hline 6 & 55 & 55 & 400 & 20 & 3.828 & 0.036 & 0.95 & 0.030 & 6 & 20 & 3.807 & 0.018 & 0.47 & 0.015 & 6 \\
\hline 7 & 50 & 50 & 400 & 40 & & & & & & 40 & 3.799 & 0.013 & 0.35 & 0.011 & 6 \\
\hline 12 & 50 & 50 & 400 & 40 & 3.746 & 0.011 & 0.30 & 0.009 & 6 & 40 & 3.807 & 0.009 & 0.23 & 0.007 & 6 \\
\hline 13 & 10 & 40 & 120 & 120 & & & & & & 120 & 4.027 & 0.022 & 0.54 & 0.018 & 6 \\
\hline 14 & 50 & 50 & 400 & 160 & 3.789 & 0.011 & 0.30 & 0.009 & 6 & 160 & 3.774 & 0.020 & 0.53 & 0.016 & 6 \\
\hline 16 & 50 & 50 & 400 & 80 & 3.749 & 0.015 & 0.40 & 0.012 & 6 & 80 & 3.802 & 0.016 & 0.41 & 0.013 & 6 \\
\hline 17 & 10 & 10 & 400 & 80 & 3.867 & 0.016 & 0.42 & 0.013 & 6 & 80 & 3.919 & 0.024 & 0.62 & 0.020 & 6 \\
\hline 18 & 50 & 50 & 400 & 50 & 3.791 & 0.026 & 0.67 & 0.021 & 6 & 50 & 3.786 & 0.054 & 1.44 & 0.044 & 6 \\
\hline 19 & 50 & 50 & 400 & 60 & 3.504 & 0.038 & 1.09 & 0.031 & 6 & 60 & 3.747 & 0.052 & 1.39 & 0.042 & 6 \\
\hline 20 & 50 & 50 & 400 & 70 & 3.755 & 0.046 & 1.23 & 0.046 & 4 & 70 & 3.809 & 0.020 & 0.52 & 0.016 & 6 \\
\hline 21 & 50 & 50 & 400 & 80 & 3.783 & 0.007 & 0.19 & 0.006 & 6 & 80 & 3.870 & 0.006 & 0.16 & 0.005 & 6 \\
\hline 22 & 50 & 50 & 400 & 40 & 3.676 & 0.054 & 1.47 & 0.044 & 6 & 40 & 3.714 & 0.027 & 0.73 & 0.022 & 6 \\
\hline 23 & 50 & 50 & 400 & 20 & 3.797 & 0.042 & 1.10 & 0.034 & 6 & 20 & 3.875 & 0.044 & 1.15 & 0.036 & 6 \\
\hline 24 & 50 & 50 & 400 & 4 & 3.883 & 0.014 & 0.37 & 0.013 & 5 & 4 & 3.941 & 0.008 & 0.19 & 0.006 & 6 \\
\hline 25 & 50 & 50 & 400 & 100 & 3.736 & 0.013 & 0.35 & 0.012 & 5 & 100 & 3.775 & 0.007 & 0.19 & 0.007 & 5 \\
\hline 26 & 10 & 5 & 800 & 160 & 3.727 & 0.019 & 0.51 & 0.016 & 6 & 160 & 3.697 & 0.009 & 0.25 & 0.008 & 6 \\
\hline 29 & & & & & & & & & & & 3.727 & 0.055 & 1.48 & 0.064 & 3 \\
\hline 30 & 50 & 50 & 400 & 100 & 3.861 & 0.039 & 1.01 & 0.032 & 6 & 100 & 3.832 & 0.045 & 1.18 & 0.037 & 6 \\
\hline 31 & 50 & 50 & 400 & 50 & 3.617 & 0.007 & 0.18 & 0.005 & 6 & 50 & 3.674 & 0.008 & 0.21 & 0.006 & 6 \\
\hline 33 & 50 & 50 & 400 & 1 & 3.677 & 0.050 & 1.35 & 0.041 & 6 & 1 & 3.806 & 0.088 & 2.31 & 0.072 & 6 \\
\hline \multicolumn{15}{|c|}{ All results (not including } & \\
\hline Mean $(\mathrm{mmol} / \mathrm{mol})$ & & & & & 3.750 & 0.026 & 0.70 & 0.022 & & & 3.824 & 0.027 & 0.70 & 0.023 & \\
\hline s.d. & & & & & 0.089 & & & & & & 0.095 & & & & \\
\hline r.s.d. $(\%)$ & & & & & 2.36 & & & & & & 2.48 & & & & \\
\hline $\mathrm{n}$ & & & & & 21 & & & & & & 24 & & & & \\
\hline \multicolumn{16}{|l|}{$>10 \mathrm{mg}$ powder } \\
\hline Mean & & & & & 3.746 & 0.027 & 0.73 & 0.023 & & & 3.820 & 0.026 & 0.69 & 0.022 & \\
\hline s.d. & & & & & 0.089 & & & & & & 0.083 & & & & \\
\hline r.s.d. $(\%)$ & & & & & 2.38 & & & & & & 2.17 & & & & \\
\hline $\mathrm{n}$ & & & & & 19 & & & & & & 20 & & & & \\
\hline \multicolumn{16}{|l|}{ Including Lab 29} \\
\hline Mean & & & & & 3.749 & 0.026 & 0.69 & 0.023 & & & & & & & \\
\hline s.d. & & & & & 0.087 & & & & & & & & & & \\
\hline r.s.d. $(\%)$ & & & & & 2.31 & & & & & & & & & & \\
\hline $\mathrm{n}$ & & & & & 22 & & & & & & & & & & \\
\hline \multicolumn{16}{|l|}{ Excluding Lab 19} \\
\hline Mean & & & & & 3.761 & 0.027 & 0.72 & 0.024 & & & & & & & \\
\hline s.d. & & & & & 0.069 & & & & & & & & & & \\
\hline r.s.d. $(\%)$ & & & & & 1.83 & & & & & & & & & & \\
\hline $\mathrm{n}$ & & & & & 21 & & & & & & & & & & \\
\hline
\end{tabular}

[36] Most of the participating laboratories used the $50 \mathrm{mg}$ sample size requested in the dissolution protocol but smaller samples of $23 \mathrm{mg}$ (Lab 4) and $10 \mathrm{mg}$ (Labs 13, 17 and 26) were also used. Exclusion of results from these laboratories had little effect on the mean values and reproducibility (Table 4), confirming the homogeneity of ECRM
752-1 for sample sizes of $10 \mathrm{mg}$ and above when solutions are analyzed after centrifuging [Greaves et al., 2005].

[37] $\mathrm{Mn} / \mathrm{Ca}$ ratios were similar from both centrifuged and noncentrifuged determinations, with $\mathrm{Mn} / \mathrm{Ca}=0.132 \mathrm{mmol} / \mathrm{mol}(0.009$ s.d. $6.6 \%$ r.s.d) 


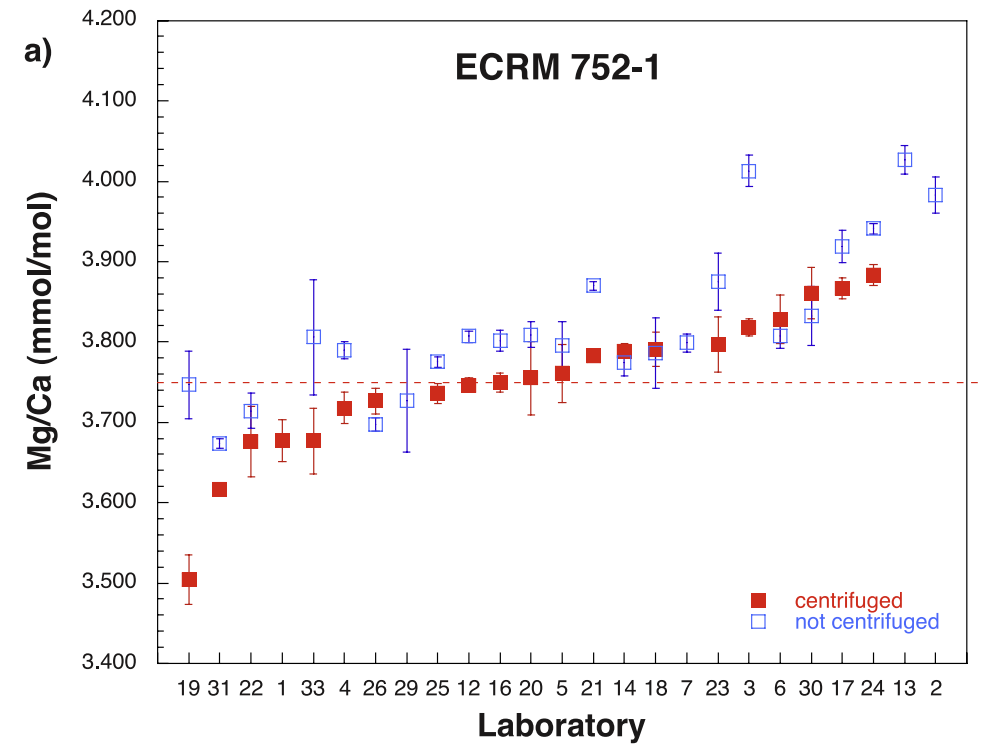

$$
\begin{array}{r}
\text { Mean } 3.749 \\
\text { s.d. } 0.087
\end{array}
$$

b)
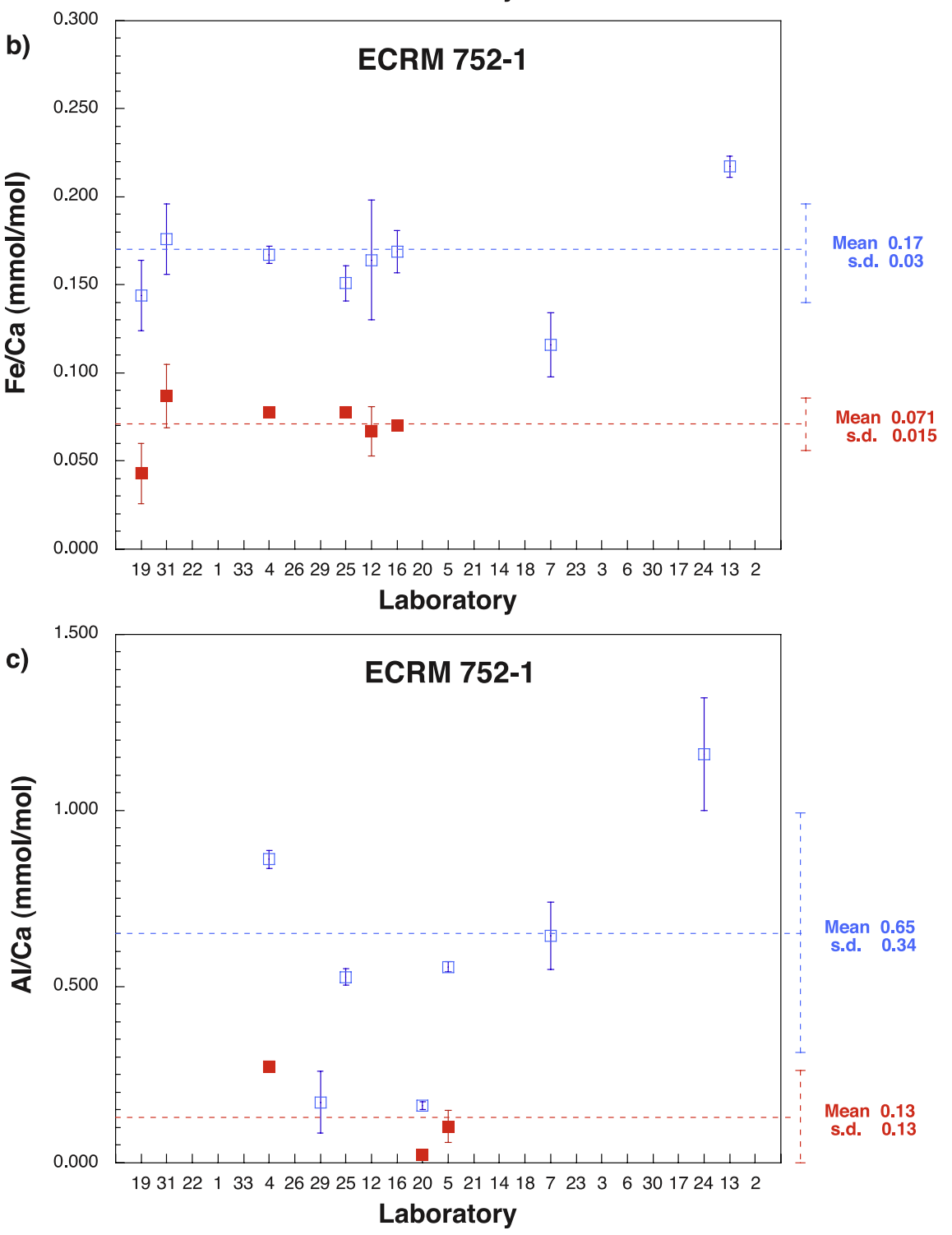

Figure 4 
on determinations by 13 laboratories without centrifuging and $\mathrm{Mn} / \mathrm{Ca}=0.132 \mathrm{mmol} / \mathrm{mol}$ (0.008 s.d. $6.3 \%$ r.s.d) on determinations by 12 laboratories after centrifuging. The low $\mathrm{Sr} / \mathrm{Ca}$ ratio in ECRM 752-1 calculated from quoted element concentrations (Table 1), reported previously [Greaves et al., 2005], was confirmed by the 21 laboratories that returned results for $\mathrm{Sr} / \mathrm{Ca}$.

[38] Statistical analysis of the results for $\mathrm{Mg} / \mathrm{Ca}$ determinations after centrifuging identified no outliers, either on the basis of high within laboratory variance (Cochran test) or extreme average values (Grubbs test), the lowest $\mathrm{Mg} / \mathrm{Ca}$ mean value (Figure $4 a$, Lab 19) falling just within the critical value of the Grubbs extreme deviation outlier test. Including results obtained using the flow through method, a mean measured $\mathrm{Mg} / \mathrm{Ca}=3.749 \mathrm{mmol} /$ mol $(0.087$ s.d., $2.31 \%$ r.s.d) was obtained on 22 determinations after centrifuging (Table 4). If the results after centrifuging from Lab 19 are excluded (see discussion in section 3.4) then mean $\mathrm{Mg} / \mathrm{Ca}=3.761 \mathrm{mmol} / \mathrm{mol}(0.069$ s.d., $1.87 \%$ r.s.d) on 21 determinations (Table 4). As found for BAM RS3, results obtained by ICPMS are statistically indistinguishable from those obtained by ICP-OES (Figure 5b).

\subsection{CMSI 1767}

[39] CMSI 1767 has the highest $\mathrm{Mg} / \mathrm{Ca}$ ratio of the three materials circulated and contains the largest contribution from noncarbonate minerals, as shown in Table 1 and confirmed by the preliminary homogeneity study (Figure 1 ). $\mathrm{Mg} / \mathrm{Ca}$ was determined in this material by twenty-four laboratories without centrifugation and twenty-two laboratories on solutions after centrifuging. The results of $\mathrm{Mg} /$ Ca determinations in CMSI 1767 are shown in Table 5, calculated using all results with the exception of four data points. Two data points were flagged as outliers by the three sigma test in results after centrifugation; one from Lab 5, one from Lab 19, and two identified as outliers in results without centrifugation; one from Lab 16 and one from Lab 4 where anomalously high $\mathrm{Mg}$ / $\mathrm{Ca}$ was associated with high $\mathrm{Al} / \mathrm{Ca}, \mathrm{Fe} / \mathrm{Ca}$ and $\mathrm{Ti} /$
Ca. The complete data set is included in auxiliary material Tables $\mathrm{S} 1-\mathrm{S} 3$. Mean $\mathrm{Mg} / \mathrm{Ca}$ ratios obtained by each laboratory are plotted in Figure $6 \mathrm{a}$ in ascending order of centrifuged values and individual measurements for $\mathrm{Mg} / \mathrm{Ca}$ determinations in solutions after centrifuging are shown in histograms in Figures $7 \mathrm{a}$ and $7 \mathrm{~b}$.

[40] Average within laboratory standard deviations for analyses of this material both with and without centrifuging were similar at 0.040 and $0.047 \mathrm{mmol} /$ mol, respectively, equivalent to within laboratory precisions of $0.71 \%$ and $0.82 \%$ r.s.d. Again, the average within laboratory precisions masked a wide range between individual laboratories, from 0.24 to $1.69 \%$ for determinations after centrifuging solutions and 0.17 to $1.88 \%$ for determinations without centrifuging (Table 5). The between laboratory precisions were approximately three times worse than average within laboratory precisions, again following the pattern found for BAM RS3 and ECRM 752-1.

[41] The high contribution of $\mathrm{Mg}$ from silicate mineral phases in this material gave significant differences between centrifuged and noncentrifuged determinations (Figure 6a) and emphasized the importance of concurrent measurements of other element ratios to monitor silicate contamination (e.g., $\mathrm{Al} / \mathrm{Ca}, \mathrm{Fe} / \mathrm{Ca}, \mathrm{Si} / \mathrm{Ca}, \mathrm{Ti} / \mathrm{Ca}$ ), as recommended for checking cleaning efficiency when determining $\mathrm{Mg} / \mathrm{Ca}$ in foraminiferal calcite [Barker et al., 2003; Rosenthal et al., 2004; Lea et al., 2005]. The same number of laboratories determined $\mathrm{Fe} / \mathrm{Ca}$ (Figure $6 \mathrm{~b}$ ) and $\mathrm{Al} / \mathrm{Ca}$ ratios (Figure 6c) in CMSI 1767 as in ECRM 752-1, with a few participants providing results for $\mathrm{Si} / \mathrm{Ca}$ and $\mathrm{Ti} / \mathrm{Ca}$ and thirteen laboratories measuring $\mathrm{Mn} /$ $\mathrm{Ca}$. Detailed results are included in the complete data set in auxiliary material Tables $\mathrm{S} 1-\mathrm{S} 3$. Fe/Ca ratios $>1 \mathrm{mmol} / \mathrm{mol}$ were measured in CMSI 1767 in solutions without centrifuging (Figure 6b), falling to $0.67 \mathrm{mmol} / \mathrm{mol}$ on centrifuging, in agreement with the results of the preliminary homogeneity study. $\mathrm{Al} / \mathrm{Ca}$ in this material was slightly higher than in ECRM 752-1with a mean of $0.84 \mathrm{mmol} /$ mol without centrifuging, falling to $0.23 \mathrm{mmol} / \mathrm{mol}$

Figure 4. ECRM 752-1. Means of results from each laboratory, without statistical rejection: (a) Mg/Ca; (b) Fe/Ca; and (c) $\mathrm{Al} / \mathrm{Ca}$. Open symbols, not centrifuged; solid symbols, centrifuged after dissolution. Error bars are \pm 2 std errors on the mean from each laboratory. Red line in Figure 4a shows interlaboratory mean and standard deviation for centrifuged analyses before statistical rejection, including flow through analysis by Lab 29. Horizontal lines in Figures $4 \mathrm{~b}$ and $4 \mathrm{c}$ show mean values of not centrifuged (blue) and centrifuged (red) data, not including Lab 29 (see text). 
a)
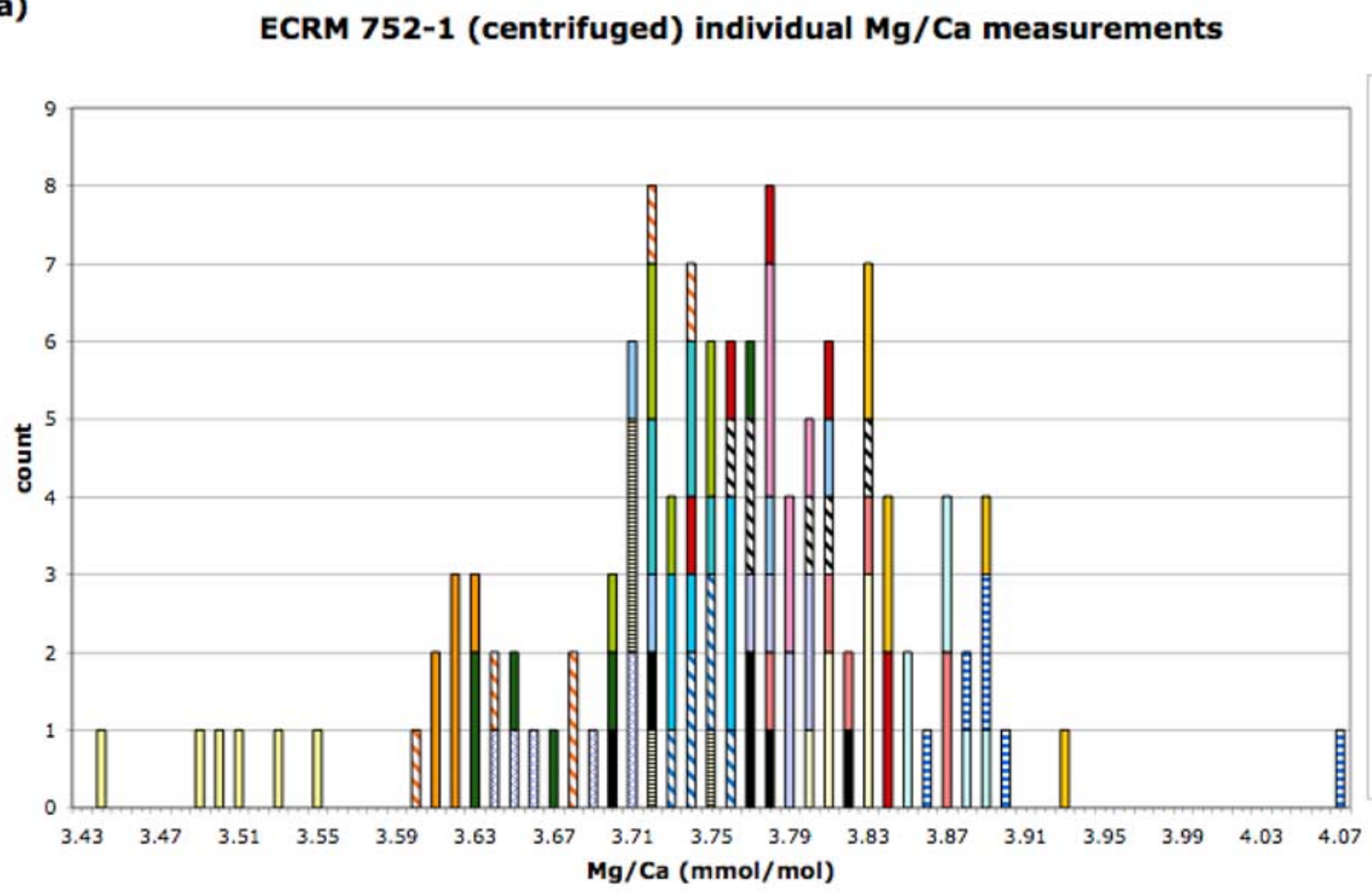

b)

ICP-MS and ICP-OES

Mg/Ca measurements for ECRM752-1(centrifuged)

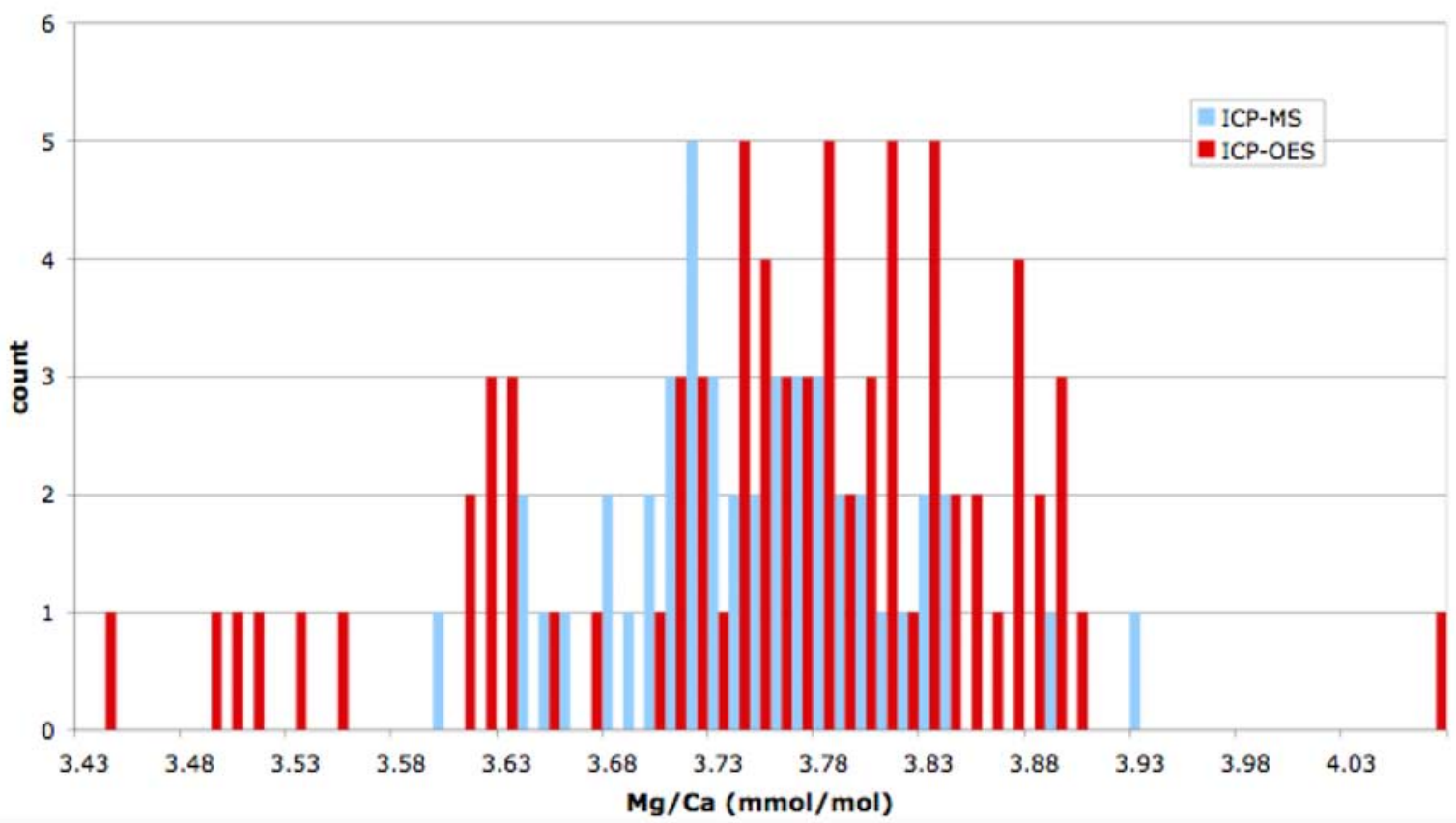

Figure 5. ECRM 752-1. Histograms of $\mathrm{Mg} / \mathrm{Ca}$ results from each laboratory for solutions after centrifuging: (a) individual measurements from each laboratory and (b) comparison of results by ICP-MS and ICP-OES. 
Table 5. Results From Each Laboratory for the Determination of $\mathrm{Mg} / \mathrm{Ca}$ in CMSI 1767

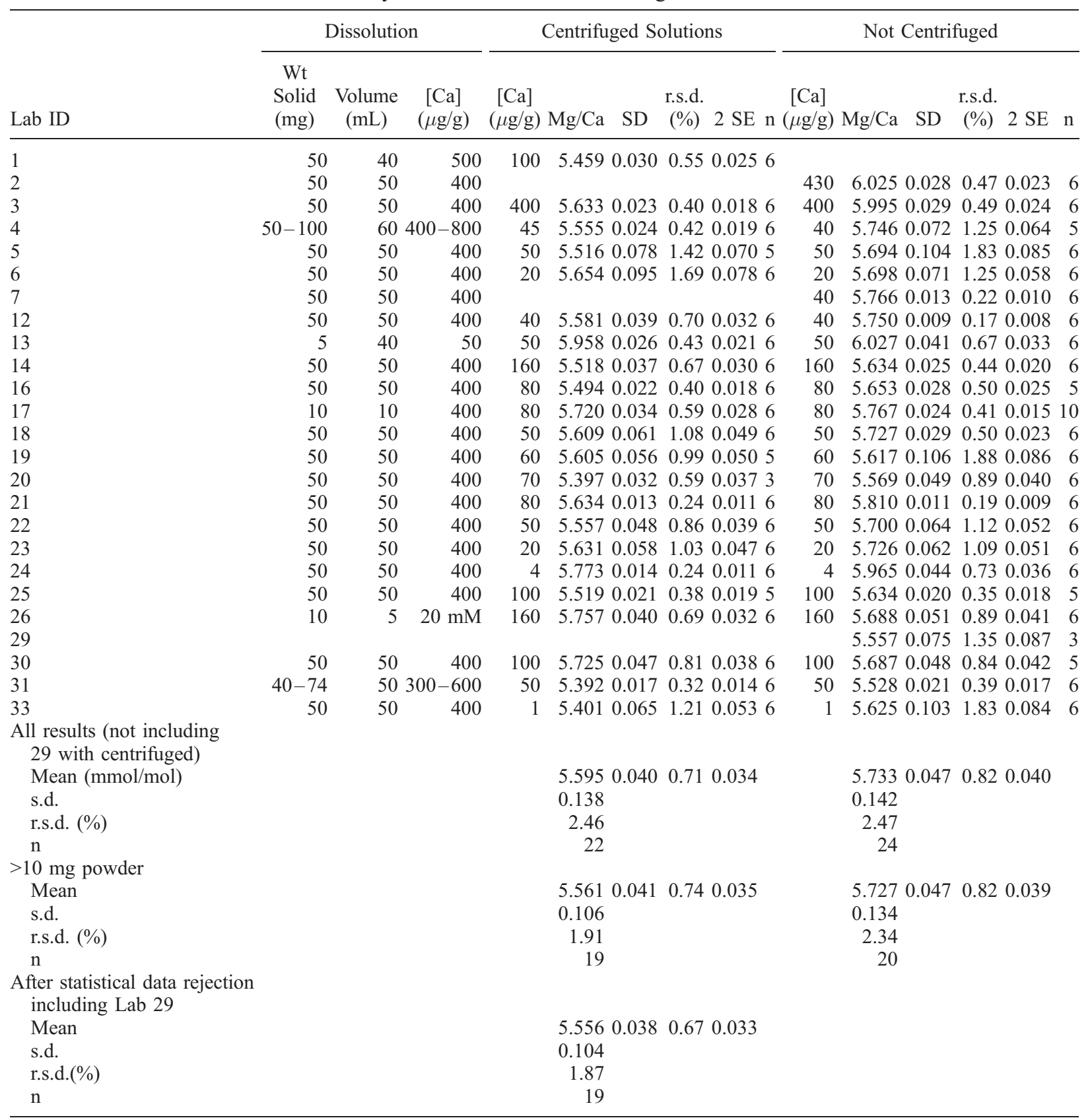

on centrifuging (Figure 6c). The flow through method (Lab 29) returned $\mathrm{Al} / \mathrm{Ca}$ of $0.41 \mathrm{mmol} /$ mol, lower than all except one of the not centrifuged determinations by other laboratories, but higher than all except one of the results after centrifuging (Figure 6c).

[42] Exclusion of results from the small $(<=10 \mathrm{mg})$ sample sizes used by laboratories 13, 17 and 26 from the reproducibility calculations in Table 5 reduced the mean $\mathrm{Mg} / \mathrm{Ca}$ obtained and improved the reproducibility, from $\mathrm{Mg} / \mathrm{Ca}=5.59 \mathrm{mmol} / \mathrm{mol}$ (0.14 s.d., $2.45 \%$ r.s.d) on 22 analyses to $\mathrm{Mg} / \mathrm{Ca}=$ $5.56 \mathrm{mmol} / \mathrm{mol}(0.11$ s.d., $1.91 \%$ r.s.d) on 19 analyses for centrifuged samples, implying that it is better to use sample weights $>10 \mathrm{mg}$ for this material. As found for both BAM RS3 and ECRM 752-1 centrifuging had little effect on $\mathrm{Mn} / \mathrm{Ca}$ in CMSI 1767 with $\mathrm{Mn} / \mathrm{Ca}=0.069 \mathrm{mmol} / \mathrm{mol}(0.006$ s.d., 9\% r.s.d) found by 13 laboratories for determinations both with and without cetrifuging. 


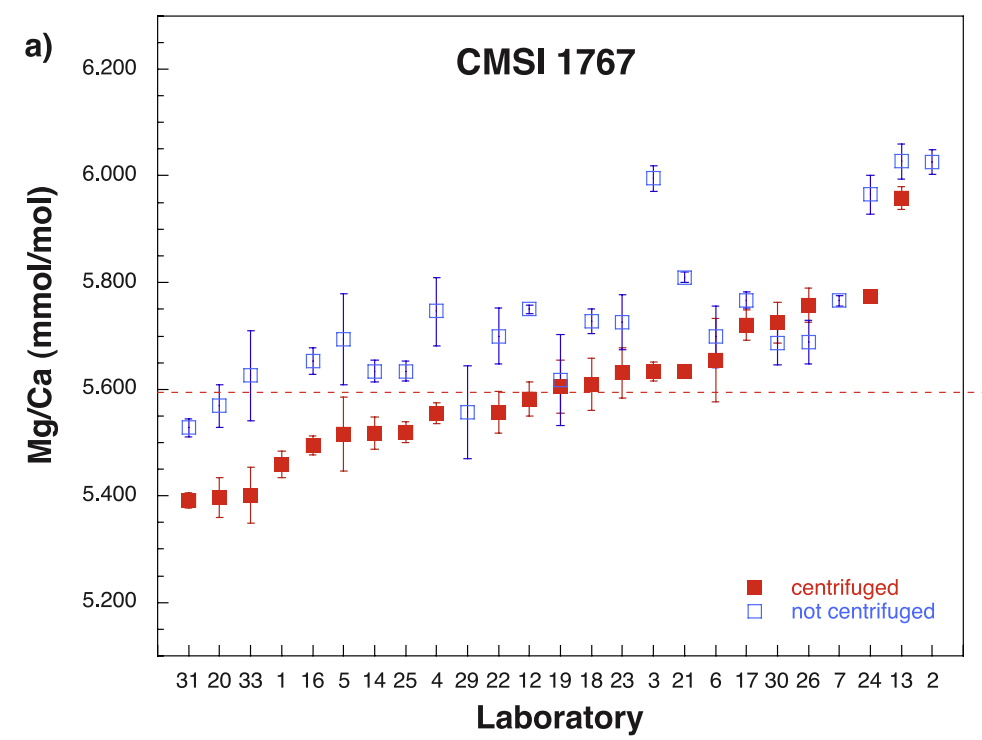

Mean 5.593 s.d. 0.135

\section{b)}
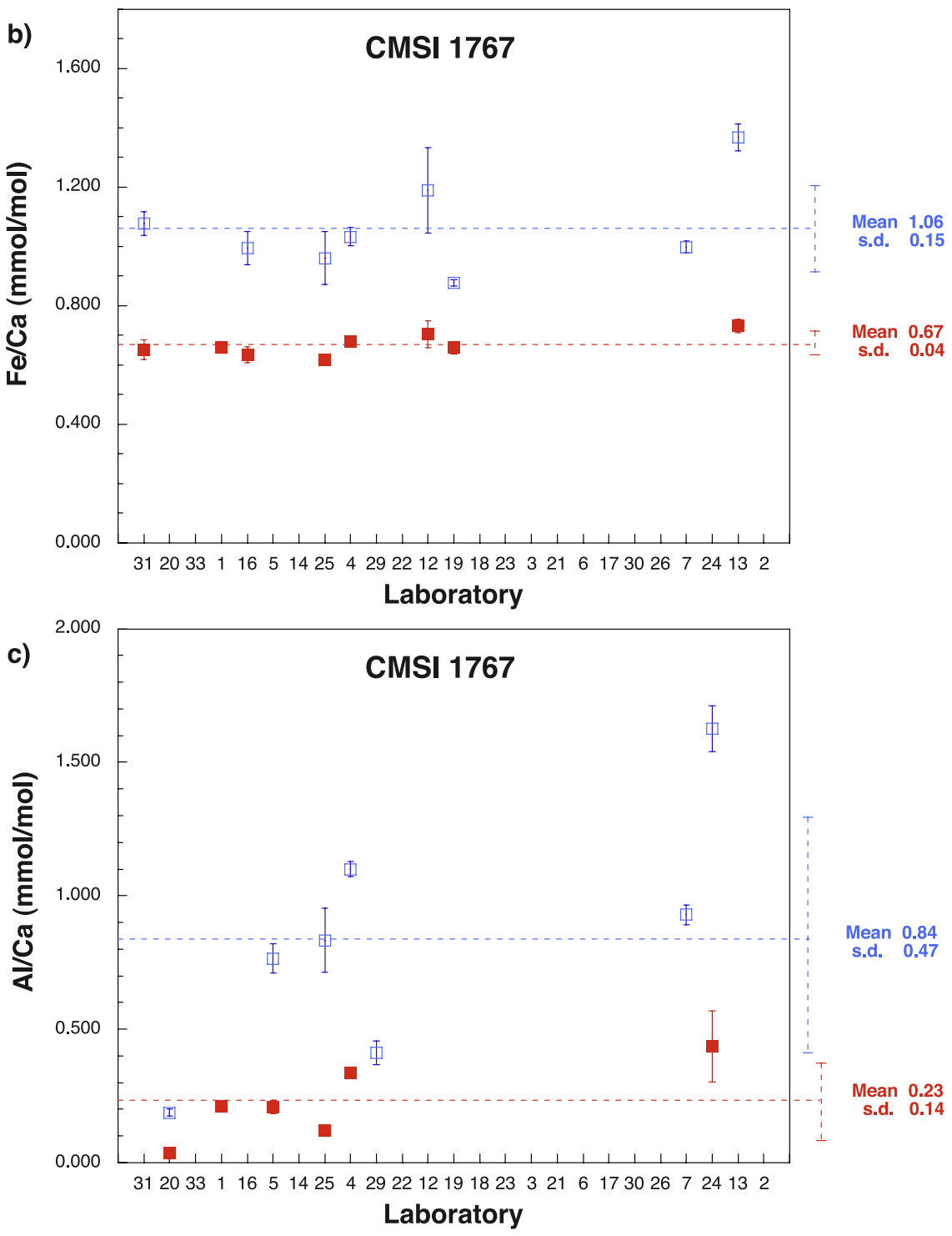

Figure 6 
[43] Statistical analysis using the Cochran test rejects results from laboratory 6 from analyses after centrifuging, on the basis of the within laboratory variance (Table 5). After exclusion of results identified by the Cochran test, no outlying average values were found on application of the Grubbs test. The results following statistical data rejection using the Cochran test give $\mathrm{Mg} / \mathrm{Ca}=$ $5.56 \mathrm{mmol} / \mathrm{mol}(0.11$ s.d., $1.87 \%$ r.s.d) on 19 determinations, consisting of 18 determinations on $>10 \mathrm{mg}$ samples after centrifuging and including lab 29 (Table 5). Results of the analysis of variance (ANOVA) are presented and discussed with those from the other two materials in section 3.4. As found from analyses of the other materials, results obtained by ICPMS are statistically indistinguishable from those obtained by ICP-OES (Figure $7 b$ ).

[44] Twenty-one laboratories returned results of $\mathrm{Sr} /$ Ca determinations in CMSI 1767, twenty on solutions after centrifuging, twenty on solutions without centrifuging and one using the flow through method (Table 6). Mean values are plotted for each laboratory in Figure 8, in ascending order of centrifuged values, using data before statistical rejection. Within laboratory precisions averaged $0.54 \%$ on centrifuged solutions and $0.65 \%$ on solutions without centrifugation, excluding the flow through analyses of laboratory 29 , or $0.80 \%$ including results of the flow through analysis (Table 6). Results with and without centrifuging solutions were in close agreement for all except two laboratories (18 and 30).

[45] The homogeneity of $\mathrm{Sr} / \mathrm{Ca}$ within CMSI 1767 is demonstrated by results from the two laboratories where small samples $(<=10 \mathrm{mg})$ were dissolved, removal of these data having a negligible effect on the mean values shown in Table 6 .

[46] Statistical analysis using the Cochran test rejected results on the basis of within laboratory variance from laboratory 29 for analyses without centrifuging, and from laboratories 6 and 23 for analyses after centrifuging (Table 6 and Figure 8). Application of the Grubbs test rejected the lowest set of values (Lab 22) giving $\mathrm{Sr} / \mathrm{Ca}=1.507 \mathrm{mmol} /$ mol (0.031 s.d., $2.06 \%$ r.s.d) on 17 determinations after centrifuging and $\mathrm{Sr} / \mathrm{Ca}=1.506 \mathrm{mmol} / \mathrm{mol}$ (0.036 s.d., $2.42 \%$ r.s.d) on 19 determinations without centrifuging (Table 6).

\subsection{Comparisons Between the Three Materials}

[47] The results of $\mathrm{Mg} / \mathrm{Ca}$ determinations in the three materials are compared in Figure 9 using the Youden plot method [Kateman and Buydens, 1993]. The Mg contents of the materials are not close enough to treat them as Youden matched pairs [Horwitz, 1995; AOAC International, 2006] but comparison plots are informative. $\mathrm{Mg} / \mathrm{Ca}$ measurements from solutions after centrifuging, including results from the flow through method (Lab 29), are plotted as two sample comparisons relative to ECRM 752-1 in Figures 9a and 9b for BAM RS3 and CMSI 1767, respectively. The large difference in $\mathrm{Mg} / \mathrm{Ca}$ between BAM RS3 and ECRM 752-1 masks other effects; Figure 9a is dominated by "noise" and random scatter about the mean. $\mathrm{Mg} / \mathrm{Ca}$ of CMSI 1767 and ECRM 752-1 are more similar, therefore the 1:1 line in Figure $9 \mathrm{~b}$ plots closer to an angle of $45^{\circ}$, and Figure $9 \mathrm{~b}$ emphasizes systematic differences between laboratories. The trend of the results in Figure 9b lies along the 1:1 line showing that in general laboratories obtaining a high, or a low, value relative to the mean in one material do so in the other, reflecting instrument calibrations among the laboratories. Outlying laboratories plot away from the trend followed by the other laboratories. For example, laboratory 19 returned a low value for $\mathrm{Mg}$ / $\mathrm{Ca}$ in ECRM 752-1 but was close to the mean for CMSI 1767 (and BAM RS3) whereas laboratory 26 returned a high value for CMSI 1767 and a value close to the mean for ECRM 752-1. This does not confirm whether values are correct, only that laboratories following the general trend are consistent. Figures 9c and 9d show the two sample comparison plots for BAM RS3 and CMSI 1767 after exclusion of $\mathrm{Mg} / \mathrm{Ca}$ data from laboratory 19 for ECRM 752-1.

Figure 6. CMSI 1767. Means of results from each laboratory, without statistical rejection: (a) $\mathrm{Mg} / \mathrm{Ca}$; (b) Fe/Ca; and (c) $\mathrm{Al} / \mathrm{Ca}$. Open symbols, not centrifuged; solid symbols, centrifuged after dissolution. Error bars are \pm 2 std errors on the mean from each laboratory. Red line in Figure 6a shows interlaboratory mean and standard deviation for centrifuged analyses before statistical rejection, including flow through analysis by Lab 29. Horizontal lines in Figures $6 \mathrm{~b}$ and $6 \mathrm{c}$ show mean values of not centrifuged (blue) and centrifuged (red) data, not including Lab 29 (see text). 
a)

CMSI 1767 (centrifuged) individual Mg/Ca measurements

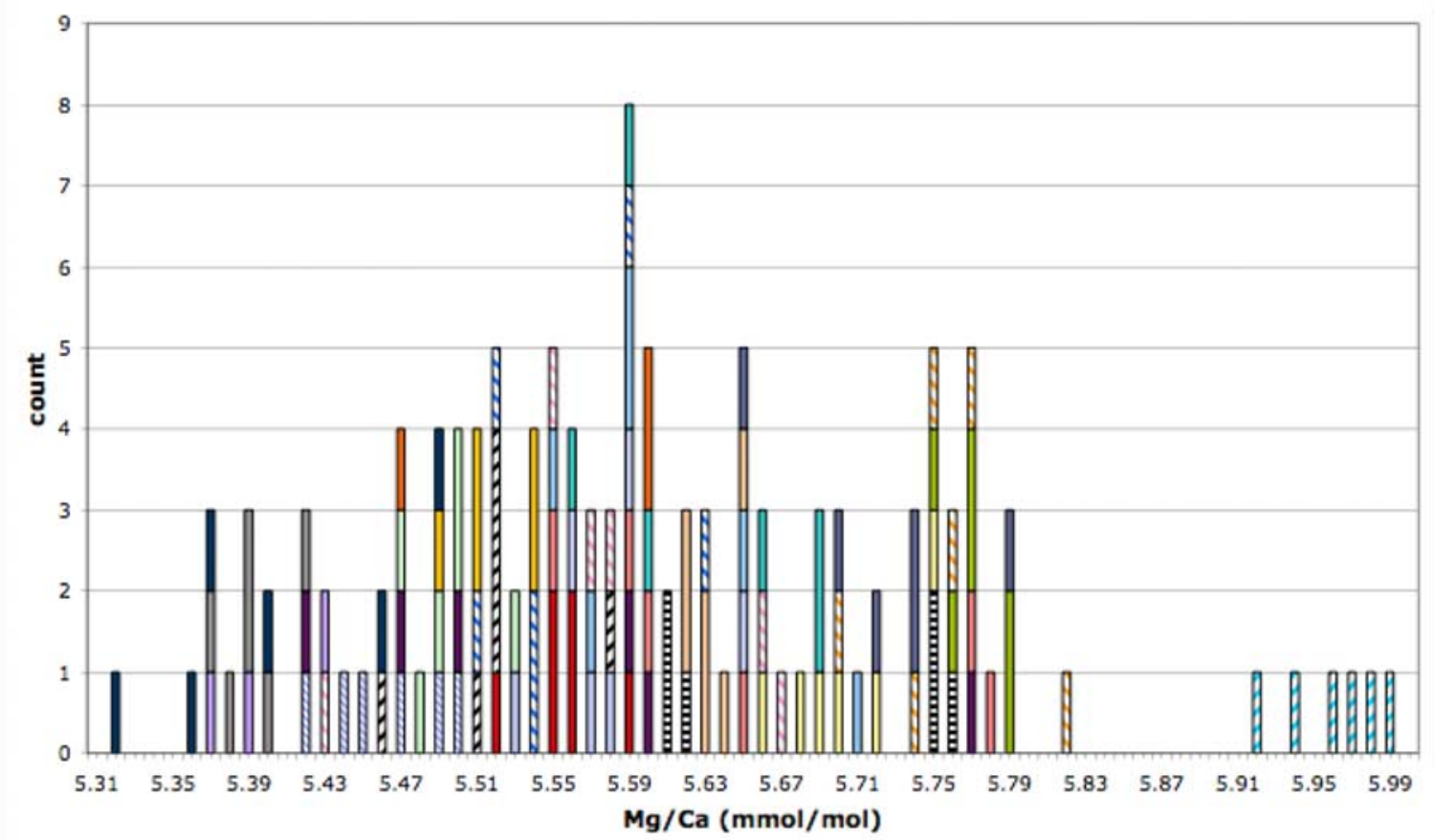

ab 33

alab 31

alab 30

Iab 29

Slab 26

lab 25

alab 24

밀 lab 23

Slab 22

lab 21

Iab 20

Slab 19

lab 18

$\square$ lab 17

lab 16

Zlab 14

Zlab 13

lab 12

- lab 7

lab 6

Llab 5

- lab 4

Elab 3

Elab 2

Slab 1

b)

ICP-OES and ICP-MS

Mg/Ca measurements for CMSI 1767 (centrifuged)

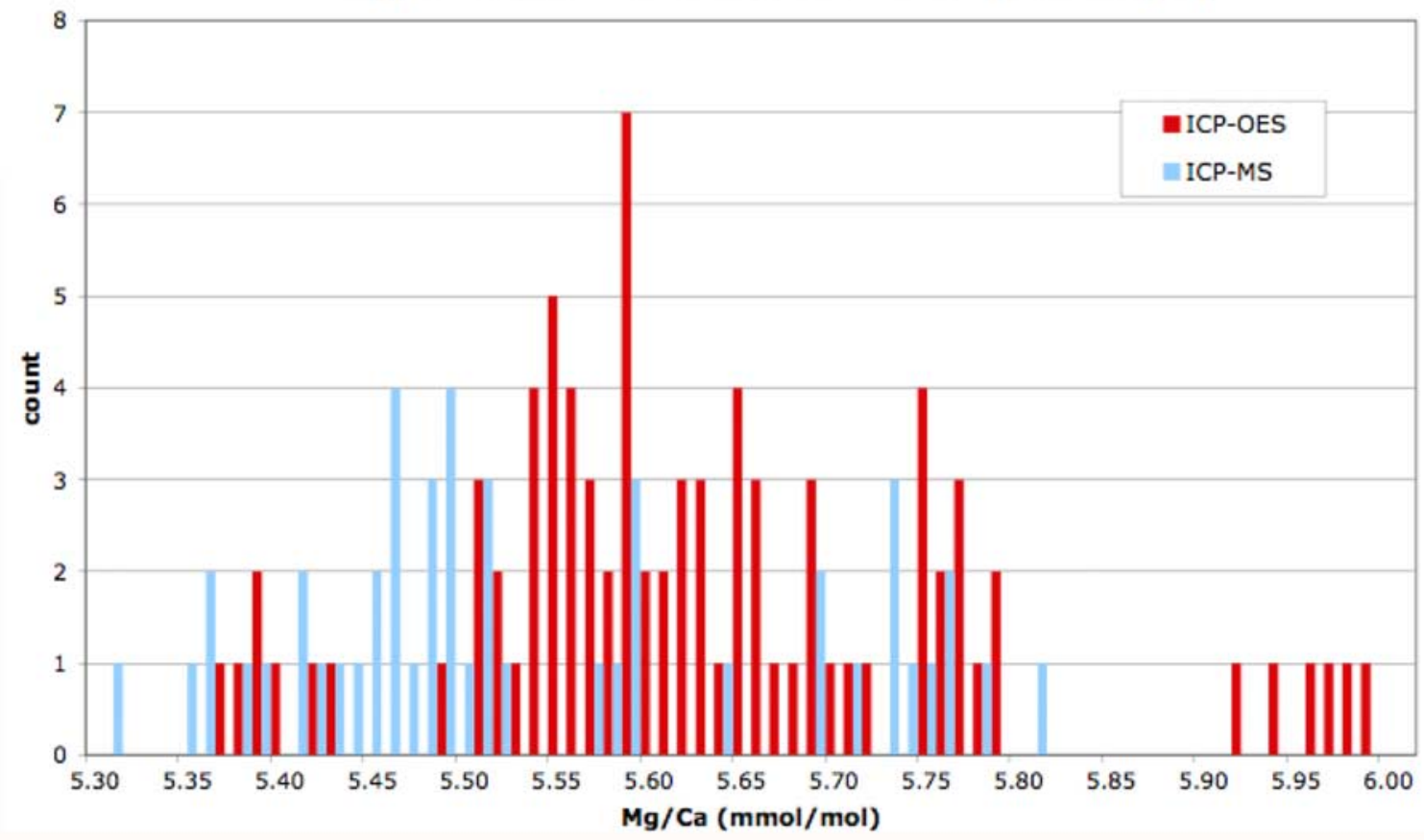

Figure 7. CMSI 1767. Histograms of $\mathrm{Mg} / \mathrm{Ca}$ results from each laboratory for solutions after centrifuging: (a) individual measurements from each laboratory and (b) comparison of results by ICP-MS and ICP-OES. 
Table 6. Results From Each Laboratory for the Determination of Sr/Ca in CMSI 1767

\begin{tabular}{|c|c|c|c|c|c|c|c|c|c|c|c|c|c|c|c|}
\hline \multirow[b]{2}{*}{ Lab ID } & \multicolumn{3}{|c|}{ Dissolution } & \multicolumn{6}{|c|}{ Centrifuged Solutions } & \multicolumn{6}{|c|}{ Not Centrifuged } \\
\hline & $\begin{array}{c}\text { Wt } \\
\text { Solid } \\
(\mathrm{mg})\end{array}$ & $\begin{array}{l}\text { Volume } \\
\text { (mL) }\end{array}$ & $\begin{array}{c}{[\mathrm{Ca}]} \\
(\mu \mathrm{g} / \mathrm{g})\end{array}$ & $\begin{array}{c}{[\mathrm{Ca}]} \\
(\mu \mathrm{g} / \mathrm{g})\end{array}$ & $\mathrm{Sr} / \mathrm{Ca}$ & SD & $\begin{array}{l}\text { r.s.d. } \\
(\%)\end{array}$ & $2 \mathrm{SE}$ & $\mathrm{n}$ & $\begin{array}{c}{[\mathrm{Ca}]} \\
(\mu \mathrm{g} / \mathrm{g})\end{array}$ & $\mathrm{Sr} / \mathrm{Ca}$ & SD & $\begin{array}{l}\text { r.s.d. } \\
(\%)\end{array}$ & $2 \mathrm{SE}$ & $\mathrm{n}$ \\
\hline 1 & 50 & 40 & 500 & 100 & 1.509 & 0.004 & 0.29 & 0.004 & 6 & & & & & & \\
\hline 2 & 50 & 50 & 400 & & & & & & & 430 & & & & & \\
\hline 3 & 50 & 50 & 400 & 400 & & & & & & 400 & & & & & \\
\hline 4 & $50-100$ & 60 & $400-800$ & 45 & 1.535 & 0.005 & 0.34 & 0.004 & 6 & 40 & 1.532 & 0.008 & 0.55 & 0.007 & 6 \\
\hline 5 & 50 & 50 & 400 & 50 & 1.442 & 0.013 & 0.91 & 0.011 & 6 & 50 & 1.442 & 0.015 & 1.06 & 0.013 & 6 \\
\hline 6 & 50 & 50 & 400 & 20 & 1.549 & 0.019 & 1.25 & 0.016 & 6 & 20 & 1.548 & 0.007 & 0.48 & 0.006 & 6 \\
\hline 7 & 50 & 50 & 400 & & & & & & & 40 & 1.453 & 0.007 & 0.46 & 0.005 & 6 \\
\hline 12 & 50 & 50 & 400 & 40 & 1.494 & 0.007 & 0.44 & 0.005 & 6 & 40 & 1.501 & 0.006 & 0.41 & 0.005 & 6 \\
\hline 13 & 5 & 40 & 50 & 50 & 1.567 & 0.010 & 0.63 & 0.008 & 6 & 50 & 1.561 & 0.013 & 0.82 & 0.010 & 6 \\
\hline 14 & 50 & 50 & 400 & 160 & 1.489 & 0.003 & 0.19 & 0.002 & 6 & 160 & 1.490 & 0.003 & 0.23 & 0.003 & 6 \\
\hline 16 & 50 & 50 & 400 & 80 & 1.513 & 0.014 & 0.92 & 0.011 & 6 & 80 & 1.523 & 0.011 & 0.75 & 0.009 & 6 \\
\hline 17 & 10 & 10 & 400 & 80 & & & & & & 80 & & & & & \\
\hline 18 & 50 & 50 & 400 & 50 & 1.517 & 0.003 & 0.21 & 0.003 & 6 & 50 & 1.471 & 0.007 & 0.46 & 0.006 & 6 \\
\hline 19 & 50 & 50 & 400 & 60 & 1.526 & 0.008 & 0.51 & 0.006 & 6 & 60 & 1.524 & 0.014 & 0.94 & 0.012 & 6 \\
\hline 20 & 50 & 50 & 400 & 70 & 1.509 & 0.002 & 0.14 & 0.002 & 3 & 70 & 1.512 & 0.012 & 0.78 & 0.010 & 6 \\
\hline 21 & 50 & 50 & 400 & 80 & 1.526 & 0.006 & 0.42 & 0.005 & 6 & 80 & 1.520 & 0.003 & 0.18 & 0.002 & 6 \\
\hline 22 & 50 & 50 & 400 & 50 & 1.224 & 0.008 & 0.68 & 0.007 & 6 & 50 & 1.217 & 0.008 & 0.64 & 0.006 & 6 \\
\hline 23 & 50 & 50 & 400 & 20 & 1.545 & 0.018 & 1.17 & 0.015 & 6 & 20 & 1.549 & 0.021 & 1.35 & 0.017 & 6 \\
\hline 24 & 50 & 50 & 400 & 4 & 1.546 & 0.007 & 0.47 & 0.006 & 6 & 4 & 1.553 & 0.004 & 0.27 & 0.003 & 6 \\
\hline 25 & 50 & 50 & 400 & 100 & 1.530 & 0.004 & 0.25 & 0.003 & 5 & 100 & 1.530 & 0.004 & 0.28 & 0.004 & 5 \\
\hline 26 & 10 & 5 & $20 \mathrm{mM}$ & 160 & 1.483 & 0.006 & 0.38 & 0.005 & 6 & 160 & 1.483 & 0.007 & 0.47 & 0.006 & 6 \\
\hline 29 & & & & & & & & & & & 1.490 & 0.056 & 3.74 & 0.064 & 3 \\
\hline 30 & 50 & 50 & 400 & 100 & 1.493 & 0.007 & 0.50 & 0.006 & 6 & 100 & 1.464 & 0.019 & 1.27 & 0.017 & 5 \\
\hline 31 & $40-74$ & 50 & $300-600$ & 50 & 1.462 & 0.004 & 0.29 & 0.003 & 6 & 50 & 1.462 & 0.004 & 0.29 & 0.003 & 6 \\
\hline 33 & 50 & 50 & 400 & 1 & 1.482 & 0.013 & 0.87 & 0.011 & 6 & 1 & 1.489 & 0.019 & 1.29 & 0.016 & 6 \\
\hline \multicolumn{16}{|c|}{$\begin{array}{l}\text { All results (not including } \\
29 \text { with centrifuged) }\end{array}$} \\
\hline Mean $(\mathrm{mmol} / \mathrm{mol})$ & & & & & 1.497 & 0.008 & 0.54 & 0.007 & & & 1.491 & 0.012 & 0.80 & 0.011 & \\
\hline s.d. & & & & & 0.071 & & & & & & 0.072 & & & & \\
\hline r.s.d. $(\%)$ & & & & & 4.76 & & & & & & 4.82 & & & & \\
\hline $\mathrm{n}$ & & & & & 20 & & & & & & 21 & & & & \\
\hline \multicolumn{16}{|l|}{$>10 \mathrm{mg}$ powder } \\
\hline Mean & & & & & 1.494 & 0.008 & 0.55 & 0.007 & & & 1.488 & 0.010 & 0.65 & 0.008 & \\
\hline s.d. & & & & & 0.073 & & & & & & 0.076 & & & & \\
\hline r.s.d. $(\%)$ & & & & & 4.91 & & & & & & 5.11 & & & & \\
\hline $\mathrm{n}$ & & & & & 18 & & & & & & 18 & & & & \\
\hline \multicolumn{16}{|c|}{ After statistical rejection } \\
\hline Mean & & & & & 1.507 & 0.007 & 0.46 & 0.006 & & & 1.506 & 0.010 & 0.65 & 0.008 & \\
\hline s.d. & & & & & 0.031 & & & & & & 0.036 & & & & \\
\hline r.s.d. $(\%)$ & & & & & 2.06 & & & & & & 2.42 & & & & \\
\hline $\mathrm{n}$ & & & & & 17 & & & & & & 19 & & & & \\
\hline
\end{tabular}

[48] Results of the analysis of variance (ANOVA) are presented in Table 7 for $\mathrm{Mg} / \mathrm{Ca}$ in BAM RS3 determined with and without centrifuging solutions, $\mathrm{Mg} / \mathrm{Ca}$ in ECRM 752-1 and $\mathrm{Mg} / \mathrm{Ca}$ in CMSI 1767 from determinations on centrifuged solutions, including results of the flow through analysis technique, and $\mathrm{Sr} / \mathrm{Ca}$ in CMSI 1767 for determinations both with and without centrifugation. The relevant unweighted statistics, intralaboratory and interlaboratory s.d. and r.s.d., have been included in Table 7 for comparison with results of the ANOVA method.

[49] The intralaboratory repeatabilities $\left(\mathrm{RSD}_{\mathrm{r}} \%\right)$ for $\mathrm{Mg} / \mathrm{Ca}$ determinations in centrifuged solutions range from $0.78 \%$ (CMSI 1767) to $1.15 \%$ (BAM RS3), becoming noticeably larger with decreasing $\mathrm{Mg} / \mathrm{Ca}$ ratios. As found from the unweighted statistics, interlaboratory reproducibility $\left(\mathrm{RSD}_{\mathrm{R}} \%\right)$ when calculated from analysis of variance is considerably worse than intralaboratory repeatability 


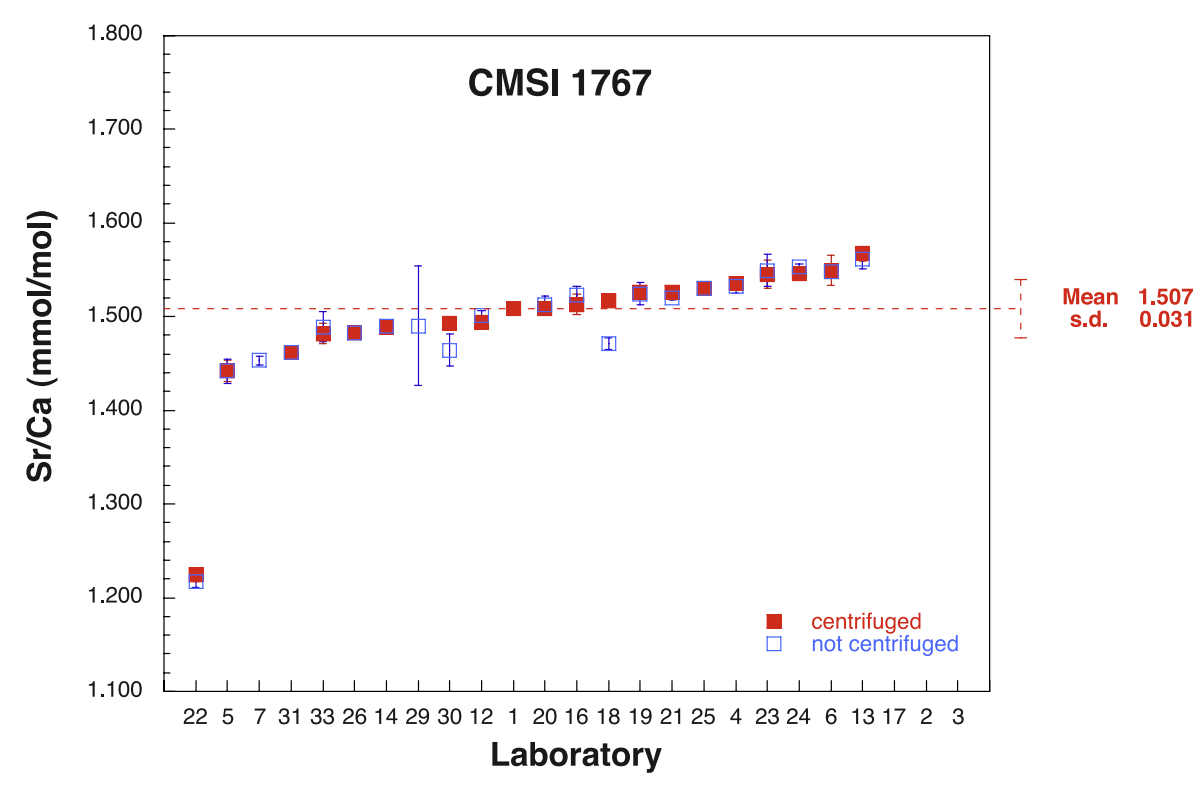

Figure 8. CMSI 1767. Sr/Ca means of results from each laboratory. Open symbols, not centrifuged; solid symbols, centrifuged after dissolution. Error bars are \pm 2 std errors on the mean from each laboratory. Red line shows the mean value from 17 laboratories after statistical rejection.

$\left(\mathrm{RSD}_{\mathrm{r}} \%\right)$, ranging from $4.45 \%$ (ECRM $\left.752-1\right)$ to $8.73 \%$ (BAM RS3) for $\mathrm{Mg} / \mathrm{Ca}$ determinations in solutions after centrifuging (Table 7). Similarly for $\mathrm{Sr} / \mathrm{Ca}$ determinations in CMSI 1767, good intralaboratory repeatability $\left(\mathrm{RSD}_{\mathrm{r}} \%\right)$ was obtained, $0.52 \%$ and $0.72 \%$ for centrifuged and not centrifuged solutions, respectively, but interlaboratory reproducibility $\left(\mathrm{RSD}_{\mathrm{R}} \%\right)$ was much worse at $5.05 \%$ and $5.92 \%$ for centrifuged and not centrifuged determinations, respectively.

[50] The interlaboratory reproducibilities include systematic errors from instrument calibrations within each laboratory and also any differences between the individual subsamples of material sent to the laboratories. However, the reproducibilities of determinations on material taken from five separate subsample bottles and analyzed by a single laboratory (Lab 25, Tables 3-6) show that inhomogeneity between subsamples is not significant. Interlaboratory variability is dominated by inconsistencies among instrument calibrations in the different laboratories.

[51] Conversion of the interlaboratory reproducibilities $\left(\mathrm{RSD}_{\mathrm{R}} \%\right)$ to temperatures using the temperature calibration of Anand et al. [2003] gives overall reproducibilities of $\sim 0.5^{\circ} \mathrm{C}$ for $\mathrm{Mg} / \mathrm{Ca}$ ratios of 3.76 and $5.56 \mathrm{mmol} / \mathrm{mol}$ (ECRM 752-1 and CMSI 1767) increasing to $\sim 1.0^{\circ} \mathrm{C}$ at $\mathrm{Mg} / \mathrm{Ca}$ of $0.79 \mathrm{mmol} / \mathrm{mol}$ (BAM RS3), for a temperature sensitivity of $9 \%$ per ${ }^{\circ} \mathrm{C}$ [Anand et al., 2003]. The repeatability $(\mathrm{r})$ and reproducibility $(\mathrm{R})$ represent the $95 \%$ confidence levels that two measurements are in agreement, within and between laboratories, respectively, assuming a normal distribution. Conversion of the reproducibility (R) to temperature [Anand et al., 2003] gives $\pm 1.4^{\circ} \mathrm{C}$ for $\mathrm{Mg} / \mathrm{Ca}$ of 5.56 and $3.76 \mathrm{mmol} / \mathrm{mol}$ (CMSI 1767 and ECRM 752-1) increasing to $\pm \sim 3^{\circ} \mathrm{C}$ for $\mathrm{Mg} /$ $\mathrm{Ca}=0.79 \mathrm{mmol} / \mathrm{mol}$ (BAM RS3 centrifuged) or \pm $\sim 4^{\circ} \mathrm{C}$ when calculated from reproducibility of BAM RS3 not centrifuged.

[52] $\mathrm{Mg} / \mathrm{Ca}$ results for the three materials (Tables 35 and 7) are lower than calculated from certified element concentrations (Table 1) because in this study small sample sizes relevant to foraminiferal calcite were used for the determination of $\mathrm{Mg} / \mathrm{Ca}$ in the carbonate fraction of the materials, whereas the certified element concentrations were determined on bulk material and represent the total contribution from all minerals present. This is reflected by the trace elements (Al, Fe, $\mathrm{Si}, \mathrm{Ti})$ which are low in carbonates and high in silicate mineral phases, and demonstrated by comparison of centrifuged and noncentrifuged determinations.

\section{Conclusions}

[53] The results of $\mathrm{Mg} / \mathrm{Ca}$ determinations in this study showed that repeatability $\left(\mathrm{RSD}_{\mathrm{r}} \%\right)$, for $\mathrm{Mg}$ / 
a)

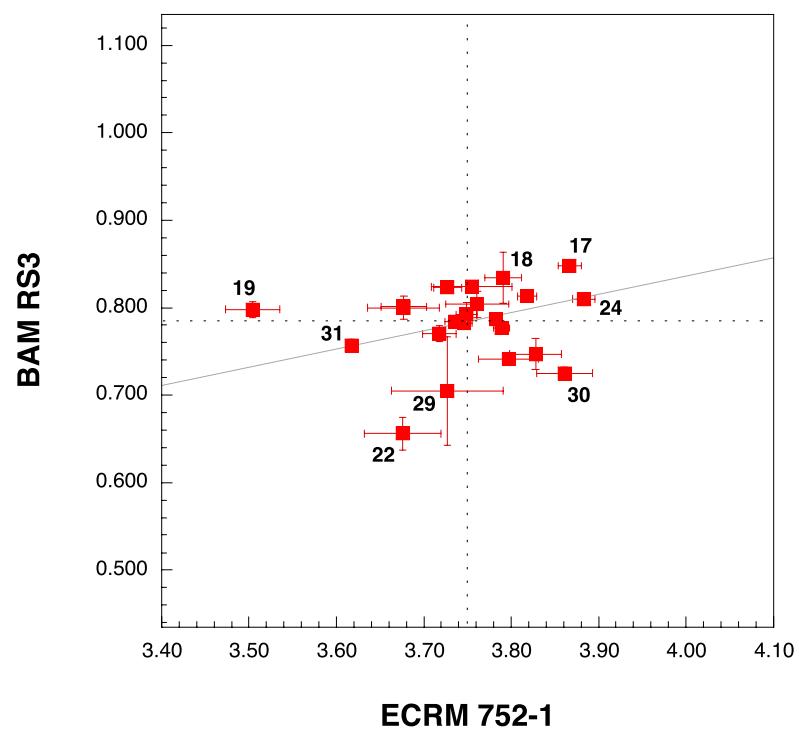

c)

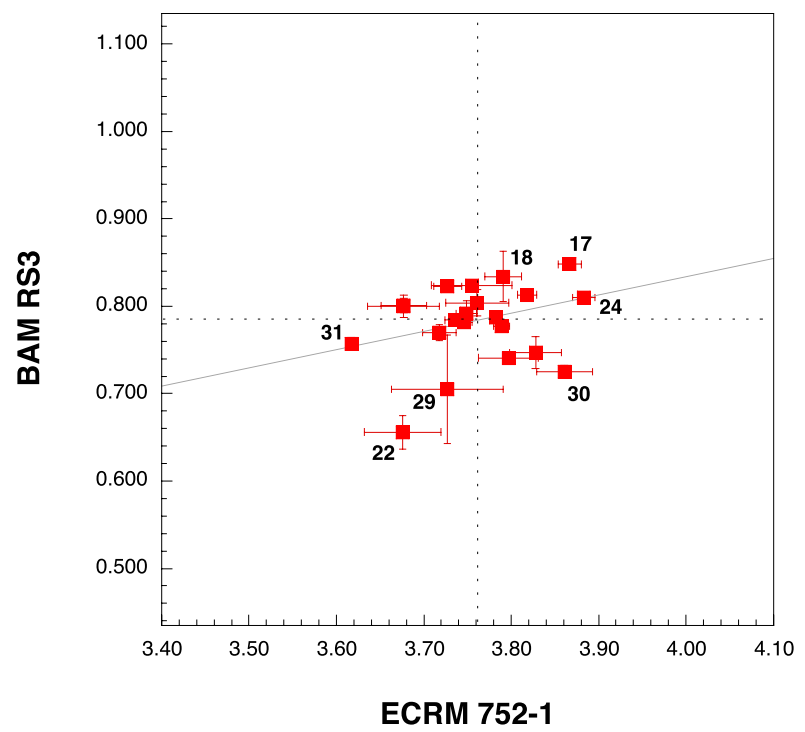

b)

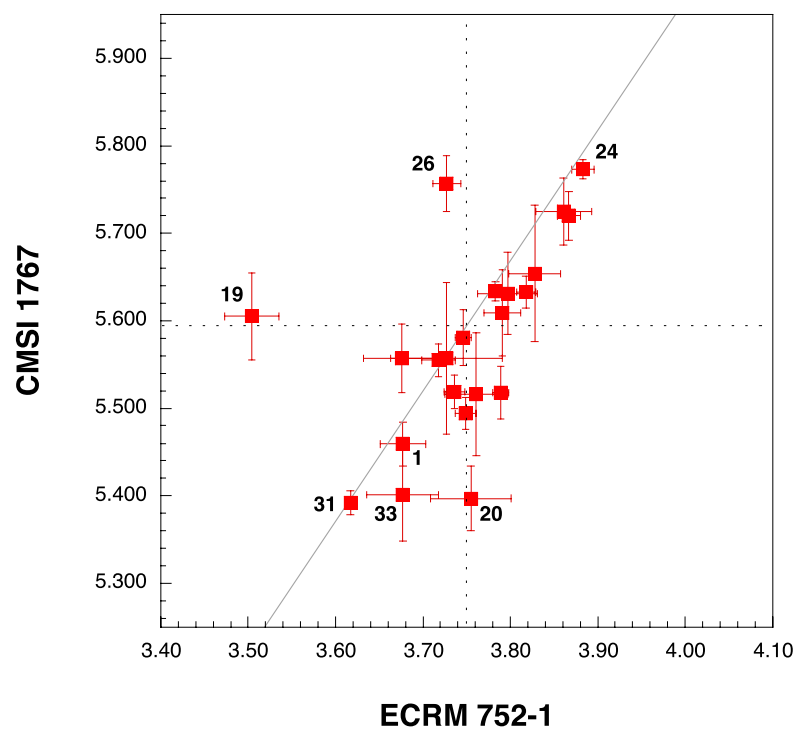

d)

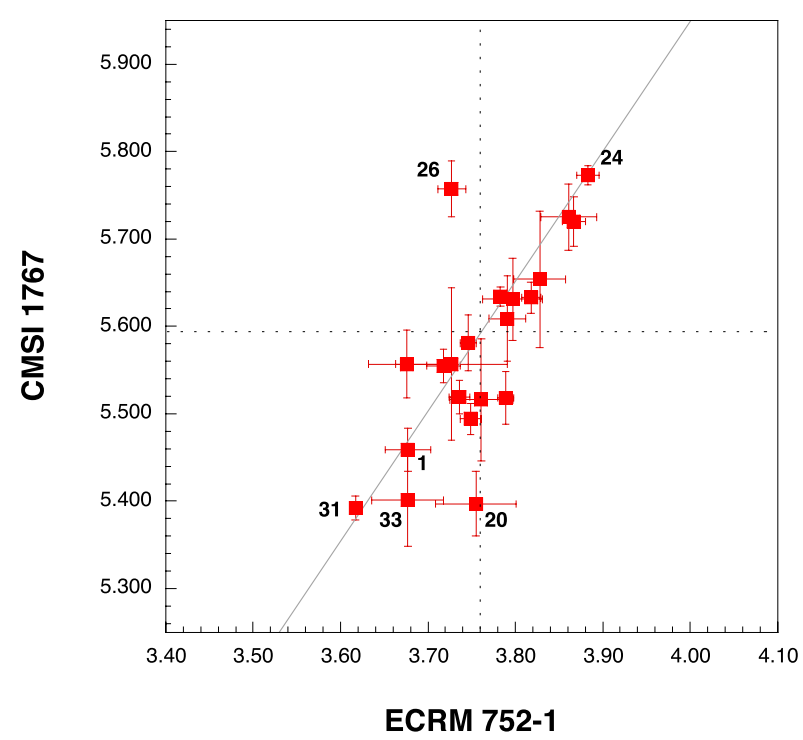

Figure 9. Comparison plots of mean $\mathrm{Mg} / \mathrm{Ca}$ results from each laboratory for determinations after centrifuging (including Lab 29): (a) BAM RS3 versus ECRM 752-1 and (b) CMSI 1767 versus ECRM 752-1. Error bars are \pm 2 std errors on the mean from each laboratory. Dotted lines show the mean of all results for each sample. Gray solid lines are the 1:1 lines through the mean. (c and d) Same as Figures 9a and 9b, omitting Lab $19 \mathrm{Mg} / \mathrm{Ca}$ data for ECRM $752-1$.

$\mathrm{Ca}$ determinations in solutions after centrifuging, increased with decreasing $\mathrm{Mg} / \mathrm{Ca}$, increasing from $0.78 \%$ at $\mathrm{Mg} / \mathrm{Ca}=5.56 \mathrm{mmol} / \mathrm{mol}(\mathrm{CMSI} 1767)$ to $0.82 \%$ at $\mathrm{Mg} / \mathrm{Ca}=3.76 \mathrm{mmol} / \mathrm{mol}(\mathrm{ECRM} 752-1)$ and $1.15 \%$ at $\mathrm{Mg} / \mathrm{Ca}=0.79 \mathrm{mmol} / \mathrm{mol}(\mathrm{BAM}$ RS3) as would be predicted for most analytical methods [Horwitz, 1982]. The average intralaboratory precisions concealed a wide range among 
Table 7. Statistical Results of Analyses of the Materials Based on ANOVA Coefficients

\begin{tabular}{|c|c|c|c|c|c|c|}
\hline $\begin{array}{c}\text { Material } \\
\text { Parameter } \\
\text { Analyses }\end{array}$ & $\begin{array}{c}\text { BAM RS3 } \\
\text { Mg/Ca } \\
\text { Centrifuged }\end{array}$ & $\begin{array}{l}\text { BAM RS3 } \\
\text { Mg/Ca Not } \\
\text { Centrifuged }\end{array}$ & $\begin{array}{c}\text { ECRM 752-1 } \\
\mathrm{Mg} / \mathrm{Ca} \\
\text { Centrifuged }\end{array}$ & $\begin{array}{c}\text { CMSI } 1767 \\
\text { Mg/Ca } \\
\text { Centrifuged }\end{array}$ & $\begin{array}{c}\text { CMSI } 1767 \\
\text { Sr/Ca } \\
\text { Centrifuged }\end{array}$ & $\begin{array}{c}\text { CMSI } 1767 \\
\text { Sr/Ca Not } \\
\text { Centrifuged }\end{array}$ \\
\hline Laboratories retained & 18 & 22 & 21 & 19 & 17 & 19 \\
\hline Not retained & 3 & 3 & 1 & 4 & 4 & 2 \\
\hline Mean & 0.791 & 0.777 & 3.762 & 5.560 & 1.507 & 1.506 \\
\hline Median & 0.795 & 0.779 & 3.767 & 5.558 & 1.509 & 1.509 \\
\hline Intralaboratory SD & 0.008 & 0.008 & 0.027 & 0.038 & 0.007 & 0.010 \\
\hline Intralaboratory RSD\% & $0.95 \%$ & $1.03 \%$ & $0.72 \%$ & $0.67 \%$ & $0.46 \%$ & $0.65 \%$ \\
\hline Interlaboratory SD & 0.030 & 0.043 & 0.069 & 0.104 & 0.031 & 0.036 \\
\hline Interlaboratory RSD\% & $3.79 \%$ & $5.52 \%$ & $1.83 \%$ & $1.86 \%$ & $2.06 \%$ & $2.42 \%$ \\
\hline $\mathrm{S}_{\mathrm{r} \text { (repeatability SD) }}$ & 0.009 & 0.016 & 0.031 & 0.043 & 0.008 & 0.011 \\
\hline $\mathrm{RSD}_{\mathrm{r}} \%$ & $1.15 \%$ & $2.06 \%$ & $0.82 \%$ & $0.78 \%$ & $0.52 \%$ & $0.74 \%$ \\
\hline Repeatability $r$ & 0.026 & 0.045 & 0.086 & 0.121 & 0.022 & 0.031 \\
\hline $\mathrm{S}_{\mathrm{R}}$ (reproducibility SD) & 0.069 & 0.102 & 0.168 & 0.248 & 0.076 & 0.089 \\
\hline $\mathrm{RSD}_{\mathrm{R}} \%$ & $8.73 \%$ & $13.09 \%$ & $4.45 \%$ & $4.47 \%$ & $5.05 \%$ & $5.92 \%$ \\
\hline Reproducibility R & 0.193 & 0.285 & 0.469 & 0.696 & 0.213 & 0.250 \\
\hline \multicolumn{7}{|c|}{ Reason for exclusion of laboratories } \\
\hline Sample size & - & - & - & $13,17,26$ & - & - \\
\hline Cochran test & $6,18,22$ & $19,29,33$ & 0 & 6 & 6,23 & 29 \\
\hline Grubbs test & 0 & 0 & 0 & 0 & 22 & 22 \\
\hline Youden plot & - & - & 19 & - & - & - \\
\hline
\end{tabular}

laboratories (Tables 3-5). Interlaboratory reproducibilities $\left(\mathrm{RSD}_{\mathrm{R}} \%\right)$ were noticeably worse than intralaboratory repeatabilities, again increasing at low $\mathrm{Mg} / \mathrm{Ca}$, from $4.5 \%$ at $\mathrm{Mg} / \mathrm{Ca}=5.56 \mathrm{mmol} / \mathrm{mol}$ and $3.76 \mathrm{mmol} / \mathrm{mol}$ (CMSI 1767 and ECRM 752-1) to $8.7 \%$ at $\mathrm{Mg} / \mathrm{Ca}=0.79 \mathrm{mmol} / \mathrm{mol}$ (BAM RS3), for $\mathrm{Mg} / \mathrm{Ca}$ determinations in centrifuged solutions. The interlaboratory variability is dominated by inconsistencies among instrument calibrations between laboratories, which need to be addressed to improve compatibility of $\mathrm{Mg} / \mathrm{Ca}$ measurements and calculated temperatures. This is particularly important when determining temperatures from the low $\mathrm{Mg}$ / $\mathrm{Ca}$ ratios associated with benthic and cold-water planktonic species of foraminifera.

[54] This study confirmed the suitability of the circulated solid standards as reference materials for foraminiferal $\mathrm{Mg} / \mathrm{Ca}$ determinations, provided that appropriate procedures are adopted in order to minimize and to monitor possible contamination from silicate mineral phases present in ECRM 7521 and CMSI 1767. The combination of $\mathrm{Mg} / \mathrm{Ca}$ determinations in ECRM 752-1 and CMSI 1767
(Figures 9b and 9d) represents an efficient way of achieving analytical consistency among laboratories, with the objective of minimizing deviations from the mean values obtained by the community. BAM RS3 was shown to be a valuable reference material for determinations at low $\mathrm{Mg} / \mathrm{Ca}$ ratios, being homogenous with a pure $\mathrm{CaCO}_{3}$ matrix. We recommend that laboratories determining low $\mathrm{Mg}$ / $\mathrm{Ca}$ ratios report results for BAM RS3 to improve compatibility of low temperature estimates. CMSI 1767 , because of its high silicate mineral content, is the most difficult of the three materials for $\mathrm{Mg} / \mathrm{Ca}$ determinations but has the advantage of an ideal $\mathrm{Sr} /$ $\mathrm{Ca}$ ratio for intercalibration of foraminiferal $\mathrm{Sr} / \mathrm{Ca}$.

\section{Acknowledgments}

[55] The manuscript was improved following constructive reviews by two anonymous reviewers and comments from the G-Cubed editor, Vincent Salters. Research funding is acknowledged in France from the IMAGES project, CNRS, the Commissariat à l'Energie Atomique, and the University Saint Quentin en Yvelines and in the UK from NERC and the Gary Comer Foundation. The project was coordinated by the first two authors, who contributed equally to this paper. 


\section{References}

Anand, P., H. Elderfield, and M. H. Conte (2003), Calibration of $\mathrm{Mg} / \mathrm{Ca}$ thermometry in planktonic foraminifera from a sediment trap time series, Paleoceanography, 18(2), 1050, doi:10.1029/2002PA000846.

Andreasen, D. H., S. Sosdian, S. Perron-Cashman, C. H. Lear, T. deGaridel-Thoron, P. Field, and Y. Rosenthal (2006), Fidelity of radially viewed ICP-OES and magnetic-sector ICP-MS measurement of $\mathrm{Mg} / \mathrm{Ca}$ and $\mathrm{Sr} / \mathrm{Ca}$ ratios in marine biogenic carbonates: Are they trustworthy together?, Geochem. Geophys. Geosyst., 7, Q10P18, doi:10.1029/2005GC001124.

AOAC International (2006), Appendix D: Guidelines for collaborative study procedures to validate characteristics of a method of analysis, in Official Methods of Analysis, 18th ed., 12 pp., Gaithersburg, Md. (Available at http://www.aoac.org/ vmeth/Manual_Part_6.pdf)

Barker, S., M. Greaves, and H. Elderfield (2003), A study of cleaning procedures used for foraminiferal $\mathrm{Mg} / \mathrm{Ca}$ paleothermometry, Geochem. Geophys. Geosyst., 4(9), 8407, doi:10.1029/2003GC000559.

Benway, H. M., B. A. Haley, G. P. Klinkhammer, and A. C. Mix (2003), Adaptation of a flow-through leaching procedure for $\mathrm{Mg} / \mathrm{Ca}$ paleothermometry, Geochem. Geophys. Geosyst., 4(2), 8403, doi:10.1029/2002GC000312.

Billups, K., and D. P. Schrag (2002), Paleotemperatures and ice volume of the past $27 \mathrm{Myr}$ revisited with paired $\mathrm{Mg} / \mathrm{Ca}$ and 180/16O measurements on benthic foraminifera, Paleoceanography, 17(1), 1003, doi:10.1029/2000PA000567.

Billups, K., and D. P. Schrag (2003), Application of benthic foraminiferal $\mathrm{Mg} / \mathrm{Ca}$ ratios to questions of Cenozoic climate change, Earth Planet. Sci. Lett., 209, 181-195, doi:10.1016/ S0012-821X(03)00067-0.

Davies, P. L. (1988), Statistical evaluation of interlaboratory tests, Fresenius Z. Anal. Chem., 331, 513-519, doi:10.1007/ BF00467041.

Dekens, P. S., D. W. Lea, D. K. Pak, and H. J. Spero (2002), Core top calibration of $\mathrm{Mg} / \mathrm{Ca}$ in tropical foraminifera: Refining paleotemperature estimation, Geochem. Geophys. Geosyst., 3(4), 1022, doi:10.1029/2001GC000200.

Elderfield, H., and G. Ganssen (2000), Past temperature and $\delta^{18} \mathrm{O}$ of surface ocean waters inferred from foraminiferal $\mathrm{Mg} / \mathrm{Ca}$ ratios, Nature, 405, 442-445, doi:10.1038/ 35013033.

Elderfield, H., M. Cooper, and G. Ganssen (2000), $\mathrm{Sr} / \mathrm{Ca}$ in multiple species of planktonic foraminifera: Implications for reconstructions of seawater $\mathrm{Sr} / \mathrm{Ca}$, Geochem. Geophys. Geosyst., l(11), 1017, doi:10.1029/1999GC000031.

Elderfield, H., J. Yu, P. Anand, T. Kiefer, and B. Nyland (2006), Calibrations for benthic foraminiferal $\mathrm{Mg} / \mathrm{Ca}$ paleothermometry and the carbonate ion hypothesis, Earth Planet. Sci. Lett., 250, 633-649, doi:10.1016/j.epsl.2006. 07.041 .

Greaves, M., S. Barker, C. Daunt, and H. Elderfield (2005), Accuracy, standardization, and interlaboratory calibration standards for foraminiferal $\mathrm{Mg} / \mathrm{Ca}$ thermometry, Geochem. Geophys. Geosyst., 6, Q02D13, doi:10.1029/2004GC000790.

Hastings, D. W., A. D. Russell, and S. R. Emerson (1998), Foraminiferal magnesium in Globeriginoides sacculifer as a paleotemperature proxy, Paleoceanography, 13, 161-169, doi:10.1029/97PA03147.

Horwitz, W. (1982), Evaluation of analytical methods used for regulation of foods and drugs, Anal. Chem., 54, 67-76, doi:10.1021/ac00238a002.
Horwitz, W. (1994), Nomenclature of interlaboratory analytical studies (IUPAC Recommendations 1994), Pure Appl. Chem., 66, 1903-1911, doi:10.1351/pac199466091903.

Horwitz, W. (1995), Protocol for the design, conduct and interpretation of method performance studies (IUPAC Technical report 1995), Pure Appl. Chem., 67, 331-343, doi:10.1351/ pac199567020331

International Standardization Organization (1994), Accuracy (trueness and precision) of measurements methods and results, ISO 5725-1994, Geneva.

Kateman, G., and L. Buydens (1993), Quality Control in Analytical Chemistry, 2nd ed., 317 pp., John Wiley, New York.

Lea, D. W. (1999), Trace elements in foraminiferal calcite, in Modern Foraminifera, edited by B. K. Sen Gupta, pp. 259 277, Springer, New York.

Lea, D. W., T. A. Mashiotta, and H. J. Spero (1999), Controls on magnesium and strontium uptake in planktonic foraminifera determined by live culturing, Geochim. Cosmochim. Acta, 63, 2369-2379, doi:10.1016/S0016-7037(99)00197-0.

Lea, D. W., D. K. Pak, and G. Paradis (2005), Influence of volcanic shards on foraminiferal $\mathrm{Mg} / \mathrm{Ca}$ in a core from the Galápagos region, Geochem. Geophys. Geosyst., 6, Q11P04, doi:10.1029/2005GC000970.

Lear, C. H., Y. Rosenthal, H. K. Coxall, and P. A. Wilson (2004), Late Eocene to early Miocene ice sheet dynamics and the global carbon cycle, Paleoceanography, 19, PA4015, doi:10.1029/2004PA001039.

Marchitto, T. M., and P. B. deMenocal (2003), Late Holocene variability of upper North Atlantic Deep Water temperature and salinity, Geochem. Geophys. Geosyst., 4(12), 1100, doi:10.1029/2003GC000598.

Martin, P. A., D. W. Lea, T. A. Mashiotta, T. Papenfuss, and M. Sarnthein (1999), Variation of foraminiferal $\mathrm{Sr} / \mathrm{Ca}$ over Quaternary glacial-interglacial cycles: Evidence for changes in mean ocean $\mathrm{Sr} / \mathrm{Ca}$ ? Geochem, Geochem. Geophys. Geosyst., 1(1), 1004, doi:10.1029/1999GC000006.

Martin, P. A., D. W. Lea, Y. Rosenthal, N. J. Shackleton, M. Sarnthein, and T. Papenfuss (2002), Quaternary deep sea temperature histories derived from benthic foraminiferal $\mathrm{Mg} / \mathrm{Ca}$, Earth Planet. Sci. Lett., 198, 193-209, doi:10.1016/S0012-821X(02)00472-7.

Mashiotta, T. A., D. W. Lea, and H. J. Spero (1999), Glacialinterglacial changes in Subantarctic sea surface temperature and $\delta^{18} \mathrm{O}$-water using foraminiferal $\mathrm{Mg}$, Earth Planet. Sci. Lett., 170, 417-432, doi:10.1016/S0012-821X(99)00116-8.

Meier, P. C., and R. E. Zünd (2000), Statistical Methods in Analytical Chemistry, 424 pp., John Wiley, New York.

Meland, M. Y., E. Jansen, H. Elderfield, T. M. Dokken, A. Olsen, and R. G. J. Bellerby (2006), $\mathrm{Mg} / \mathrm{Ca}$ ratios in the planktonic foraminifer Neogloboquadrina pachyderma (sinistral) in the northern North Atlantic/Nordic Seas, Geochem. Geophys. Geosyst., 7, Q06P14, doi:10.1029/2005GC001078.

Mortyn, P. G., H. Elderfield, P. Anand, and M. Greaves (2005), An evaluation of controls on planktonic foraminiferal $\mathrm{Sr} / \mathrm{Ca}$ : Comparison of water column and core-top data from a North Atlantic transect, Geochem. Geophys. Geosyst., 6, Q12007, doi:10.1029/2005GC001047.

Nilsson, T., R. Ferrari, and S. Facchetti (1997), Interlaboratory studies for the validation of solid-phase microextraction for the quantitative analysis of volatile organic compounds in aqueous samples, Anal. Chim. Acta, 356, 113-123, doi:10.1016/S0003-2670(97)00526-6.

Nurnberg, D., J. Bijma, and C. Hemleben (1996), Assessing the reliability of magnesium in foraminiferal calcite as a proxy for water mass temperatures, Geochim. Cosmochim. Acta, 60, 803-814, doi:10.1016/0016-7037(95)00446-7. 
Nyland, B. F., E. Jansen, H. Elderfield, and C. Andersson (2006), Neogloboquadrina pachyderma (dex. and sin.) $\mathrm{Mg} /$ $\mathrm{Ca}$ and $\delta^{18} \mathrm{O}$ records from the Norwegian Sea, Geochem. Geophys. Geosyst., 7, Q10P17, doi:10.1029/2005GC001055.

Pak, D. K., D. W. Lea, and J. P. Kennett (2004), Seasonal and interannual variation in Santa Barbara Basin water temperatures observed in sediment trap foraminiferal $\mathrm{Mg} / \mathrm{Ca}$, Geochem. Geophys. Geosyst., 5, Q12008, doi:10.1029/2004GC000760.

Rosell-Melé, A., et al. (2001), Precision of the current methods to measure the alkenone proxy $\mathrm{U} 37 \mathrm{~K}$ ( and absolute alkenone abundance in sediments: Results of an interlaboratory comparison study, Geochem. Geophys. Geosyst., 2(7), 1046, doi:10.1029/2000GC000141.

Rosenthal, Y., G. P. Lohmann, K. C. Lohmann, and R. M. Sherrell (2000), Incorporation and preservation of $\mathrm{Mg}$ in Globigerinoides sacculifer: Implications for reconstructing the temperature and ${ }^{18} \mathrm{O} /{ }^{16} \mathrm{O}$ of seawater, Paleoceanography, $15,134-135$.
Rosenthal, Y., et al. (2004), Interlaboratory comparison study of $\mathrm{Mg} / \mathrm{Ca}$ and $\mathrm{Sr} / \mathrm{Ca}$ measurements in planktonic foraminifera for paleoceanographic research, Geochem. Geophys. Geosyst., 5, Q04D09, doi:10.1029/2003GC000650.

Shen, C., D. W. Hastings, T. Lee, C. Chiu, M. Lee, K. Wei, and R. L. Edwards (2001), High precision glacial-interglacial benthic foraminiferal $\mathrm{Sr} / \mathrm{Ca}$ records from the eastern equatorial Atlantic Ocean and Caribbean Sea, Earth Planet. Sci., 190, 197-209, doi:10.1016/S0012-821X(01)00391-0.

Stoll, H. M., D. P. Schrag, and S. C. Clemens (1999), Are seawater $\mathrm{Sr} / \mathrm{Ca}$ variations preserved in Quaternary foraminifera?, Geochim. Cosmochim. Acta, 63, 3535-3547, doi:10.1016/S0016-7037(99)00129-5.

von Langen, P. J., D. K. Pak, H. J. Spero, and D. W. Lea (2005), Effects of temperature on $\mathrm{Mg} / \mathrm{Ca}$ in neogloboquadrinid shells determined by live culturing, Geochem. Geophys. Geosyst., 6, Q10P03, doi:10.1029/2005GC000989. 